\title{
Shear stress partitioning in large patches of roughness in the atmospheric inertial sublayer
}

\author{
John A. Gillies • William G. Nickling • James King
}

Received 11 November 2005; Accepted 12 June $2006 /$

Published online: 5 August 2006

(C) Springer Science+Business Media B.V. 2006

\begin{abstract}
Drag partition measurements were made in the atmospheric inertial sublayer for six roughness configurations made up of solid elements in staggered arrays of different roughness densities. The roughness was in the form of a patch within a large open area and in the shape of an equilateral triangle with $60 \mathrm{~m}$ long sides. Measurements were obtained of the total shear stress $(\tau)$ acting on the surfaces, the surface shear stress on the ground between the elements $\left(\tau_{\mathrm{S}}\right)$ and the drag force on the elements for each roughness array. The measurements indicated that $\tau_{\mathrm{S}}$ quickly reduced near the leading edge of the roughness compared with $\tau$, and a $\tau_{\mathrm{S}}$ minimum occurs at a normalized distance $(x / h$, where $h$ is element height) of $\approx-42$ (downwind of the roughness leading edge is negative), then recovers to a relatively stable value. The location of the minimum appears to scale with element height and not roughness density. The force on the elements decreases exponentially with normalized downwind distance and this rate of change scales with the roughness density, with the rate of change increasing as roughness density increases. Average $\tau_{\mathrm{S}}: \tau$ values for the six roughness surfaces scale predictably as a function of roughness density and in accordance with a shear stress partitioning model. The shear stress partitioning model performed very well in predicting the amount of surface shear stress, given knowledge of the stated input parameters for these patches of roughness. As the shear stress partitioning relationship within the roughness appears to come into equilibrium faster for smaller roughness element sizes it would also appear the
\end{abstract}

\footnotetext{
J. A. Gillies ( $ه)$

Particle Emissions Measurement Laboratory,

Division of Atmospheric Sciences,

Desert Research Institute,

2215 Raggio Parkway, Reno, NV 89512, USA

e-mail: jackg@dri.edu

W. G. Nickling · J. King

Wind Erosion Laboratory, Department of Geography,

University of Guelph,

Guelph ON, Canada N1G 2W1
} 
shear stress partitioning model can be applied with confidence for smaller patches of smaller roughness elements than those used in this experiment.

Keywords Atmospheric inertial sublayer - Drag partition - Roughness arrays · Shear stress partitioning

\section{List of Symbols}

$A_{\mathrm{f}} \quad$ frontal area of roughness elements $\left(\mathrm{m}^{2}\right)$

$A_{\mathrm{u}} \quad$ unit area over which surface shear stress associated with a roughness element is distributed $\left(\mathrm{m}^{2}\right)$

$b \quad$ element breadth (m)

$C d \quad$ surface drag coefficient

$C d_{\mathrm{e}} \quad$ roughness element drag coefficient

$C d_{\mathrm{r}} \quad$ rough surface drag coefficient

$C d_{\mathrm{s}} \quad$ smooth surface drag coefficient

$\mathrm{cv} \quad$ coefficient of variation

$d \quad$ displacement height (m)

$F \quad$ force on a roughness element (N)

$g \quad$ acceleration due to gravity $\left(\mathrm{m} \mathrm{s}^{-2}\right)$

$h \quad$ element height (m)

IBL internal boundary layer

ISL inertial sublayer

$m \quad$ empirical constant between 0 and 1

$n$ number of roughness elements occupying the ground area of the roughness array

NDD normalized downwind distance $(x / h)$

NED normalized element drag

$R \quad$ average friction velocity ratio

$R_{1} \quad$ local friction velocity ratio at different positions in a roughness array

Re Reynolds number

$R_{\mathrm{t}} \quad$ threshold wind friction velocity ratio

$\mathrm{SD} \quad$ standard deviation of a mean value

$u \quad$ wind speed $\left(\mathrm{m} \mathrm{s}^{-1}\right)$

$u_{*} \quad$ wind friction velocity $\left(\mathrm{m} \mathrm{s}^{-1}\right)$

$u_{* \mathrm{t} \mathrm{R}} \quad$ threshold wind friction velocity with roughness elements $\left(\mathrm{m} \mathrm{s}^{-1}\right)$

$u_{* \mathrm{tS}} \quad$ threshold wind friction velocity of bare surface $\left(\mathrm{m} \mathrm{s}^{-1}\right)$

$x \quad$ downwind distance $(\mathrm{m})$

$z \quad$ reference height above surface $(\mathrm{m})$

$z_{\mathrm{w}} \quad$ roughness sublayer height $(\mathrm{m})$

$z_{\mathrm{O}} \quad$ aerodynamic roughness length $(\mathrm{m})$

$\beta \quad$ ratio of element to surface drag coefficients

$\varphi_{\mathrm{m}} \quad$ dimensionless wind speed gradient

$\kappa \quad$ von Kármán constant (0.4)

$\lambda$ roughness density

$\mu \quad$ molecular viscosity $\left(\mathrm{N} \mathrm{s} \mathrm{m}^{-2}\right)$

$\rho_{\mathrm{a}} \quad$ air density $\left(\mathrm{kg} \mathrm{m}^{-3}\right)$

$\sigma \quad$ roughness element basal area to frontal area ratio

$\tau \quad$ total surface shear stress $\left(\mathrm{N} \mathrm{m}^{-2}\right)$ 
$\tau_{\mathrm{S}} \quad$ surface shear stress on the area not covered by the roughness elements $\left(\mathrm{N} \mathrm{m}^{-2}\right)$ $\tau_{\mathrm{R}} \quad$ surface shear stress attributed to the roughness elements $\left(\mathrm{N} \mathrm{m}^{-2}\right)$

\section{Introduction}

The presence of roughness elements on the surface such as vegetation, cobbles, or boulders increases the total drag as compared to a smooth surface, providing a degree of shelter that results in reduced surface shear stress between the roughness elements. The effect of roughness elements on the drag forces and shear stresses at the surface was first studied in detail by Schlichting (1936). He stated that the total force imparted to a rough surface can be partitioned into a force acting on the roughness and a force acting on the intervening surface. As the quantity of roughness elements is increased, both total drag and roughness drag increase while the force acting on the surface decreases.

Understanding the controls of roughness on shear stress partitioning has important ramifications for successfully predicting how surface roughness affects the entrainment and transport of sediment by wind on the Earth, particularly with regard to environmental and agricultural applications (e.g., wind erosion of agricultural soils, dune stabilization projects, sediment transport in rangelands). There are also important applications for Mars because aeolian processes affect the evolution of the Martian surface to a much greater degree than they do on Earth (Malin et al. 1998; Wilson and Zimbelman 2004).

In this paper shear-stress partitioning measurements for six different surface roughness configurations composed of the same size (solid) roughness elements in the atmospheric inertial sublayer (ISL) are reported. The ISL is defined as the zone of airflow in which the dimensionless wind speed gradient $\varphi$ of value unity is represented by the equation (Weiringa 1993)

$$
\phi \equiv\left(\frac{\kappa z}{u_{*}}\right) \frac{\partial u}{\partial z}=1
$$

where $\kappa$ is the von Kármán constant $(0.4), z$ is a reference height $(\mathrm{m}), u_{*}$ is wind friction velocity $\left(\mathrm{m} \mathrm{s}^{-1}\right), u$ is wind speed $\left(\mathrm{m} \mathrm{s}^{-1}\right)$. Equation 1 applies to conditions of neutral thermal stratification.

Due to the size and number of the roughness elements utilized, the rough surfaces constructed for this experiment are in reality representative of large patches of roughness in which sediment transport may be initiated and/or through which sand may be transported by wind. The occurrence of alternating patches of smooth and roughened surfaces in nature are frequently found in terrestrial deserts and semi-arid environments where the roughness elements consist of isolated cobbles and boulders or patches of rocks and/or sparse vegetation in isolation or in some community structure (e.g., Okin and Gillette 2001). Similar types of rough surfaces with cobbles and boulders also present evidence of sand entrainment and transport, which has been observed on the surface of Mars by the Mars Exploration Rover Mission (http://marsrovers.jpl.nasa.gov/home/).

The acquired shear-stress partitioning data from this study are subsequently used to evaluate the performance of a model developed by Raupach (1992), which was later modified by Raupach et al. (1993) to predict the partitioning of shear-stress within the established roughness configurations. This model predicts the shear-stress partitioning ratio, i.e., the percentage reduction in shear stress on the intervening surface 
between the roughness elements as compared to the surface in the absence of those elements (Wolfe and Nickling 1996), based on knowledge of the geometric properties of the roughness elements, the characteristic drag coefficients of the elements and the surface, and the assumed effect these elements have on the spatial distribution of the mean and maximum shear stresses.

Other studies have measured shear-stress partitioning in wind-tunnel experiments (e.g., Marshall 1971; Lyles and Allison 1975; Crawley and Nickling 2003) and in the field where the roughness elements have typically been porous vegetation (e.g., Musick and Gillette 1990; Wolfe and Nickling 1996; Wyatt and Nickling 1997; Luttmer 2002; Lancaster and Baas 1998) and found reasonable agreement with the Raupach et al. (1993) model (King et al. 2005). The study presented herein represents the first such one that was carried out at the full field scale for which the total shear stress $(\tau)$ in the ISL, the shear stress on the intervening surface $\left(\tau_{\mathrm{S}}\right)$, and the force of drag on the elements were measured simultaneously allowing for closure on the shear-stress partitioning relationship. The measurement of these three components of the partition system was accomplished with traditional observations of the vertical profile of wind speed using anemometers to estimate $\tau$, skin friction meters (Irwin sensors) to measure both $\tau$ and $\tau_{\mathrm{S}}$, and drag balances to measure the force on the elements, from which stress on the roughness elements $\left(\tau_{\mathrm{R}}\right)$ can be estimated. The roughness configurations were also under strict control in this experiment as they were constructed to rigorous dimensional standards.

\section{Background}

Raupach (1992) provided a detailed re-evaluation of shear-stress partitioning and brought it into the context of wind erosion, and sediment entrainment and transport by wind. He defined the partitioning of $\tau$ on a rough surface as stated by Schlichting (1936) (i.e., $\tau=\tau_{\mathrm{S}}+\tau_{\mathrm{R}}$ ) in terms of surface and element drag coefficients, roughness density, wind speed at a reference height, and wind friction velocity

$$
\tau=\tau_{\mathrm{S}}+\tau_{\mathrm{R}}=\rho_{\mathrm{a}} u_{z}^{2}\left\{C d_{\mathrm{S}} \exp \left[-c_{1}\left(\frac{u_{z}}{u_{*}}\right) \lambda\right]+\lambda C d_{\mathrm{e}} \exp \left[-c_{2}\left(\frac{u_{z}}{u_{*}}\right) \lambda\right]\right\},
$$

where $\rho_{\mathrm{a}}$ is air density $\left(\mathrm{kg} \mathrm{m}^{-3}\right), u_{z}$ is wind speed $\left(\mathrm{m} \mathrm{s}^{-1}\right)$ at height $z(\mathrm{~m}), C d_{\mathrm{S}}$ is the intervening surface drag coefficient, $C d_{\mathrm{e}}$ is the drag coefficient of an isolated, surface mounted roughness element, and $\lambda$ is roughness density. Friction velocity is defined as

$$
u_{*}=\sqrt{\tau / \rho_{\mathrm{a}}},
$$

deduced from that portion of the neutral atmospheric boundary layer where the logarithmic law applies (i.e., Eq. 1).

$C d_{\mathrm{S}}$ in Eq. 2 is defined by Raupach (1992) as

$$
C d_{\mathrm{S}}=\frac{\tau_{\mathrm{S}}}{\rho_{\mathrm{a}} u_{z}^{2}}
$$

and $C d_{\mathrm{e}}$ as

$$
C d_{\mathrm{e}}=\frac{F}{\rho_{\mathrm{a}} A u_{z}^{2}},
$$


where $F$ is force on the element $(\mathrm{N})$ and $A$ is frontal area of the element $\left(\mathrm{m}^{2}\right)$. The roughness density $(\lambda)$ is defined as

$$
\lambda=n b h / S,
$$

where $n$ is the number of roughness elements occupying the ground area $S\left(\mathrm{~m}^{2}\right), b$ is element breadth $(\mathrm{m})$, and $h$ is element height $(\mathrm{m})$.

Raupach (1992) assumed that $c_{1}$ and $c_{2}$ are coefficients that are equal and used to support his argument that individual elements shelter the ground and each other with the same efficiency. Raupach (1992) demonstrates that below $\lambda \leq 0.1$ the effect of $c$ is diminished because the partitioning effect resulting from the drag and aerodynamic parameters is independent of $c$. In this experiment the $\lambda$ values for the roughness arrays were $<0.1$.

Raupach et al. (1993), building on the stress partition theory development of Raupach (1992), proposed a physically based model for the partitioning of wind shear between solid elements with well-defined wakes and the surface between the elements. This geometric- and drag coefficient-based predictive model allows the user to specify available inputs to describe most environments and generate a ratio $\left(R_{\mathrm{t}}\right)$ that characterizes the erosion threshold of an initially bare erodible surface with the threshold once non-erodible elements are present.

The Raupach et al. (1993) model is expressed as:

$$
R_{\mathrm{t}}=\frac{u_{* \mathrm{t} \mathrm{S}}}{u_{* \mathrm{tR}}}=\frac{1}{(1-m \sigma \lambda)^{0.5}(1+m \beta \lambda)^{0.5}},
$$

where $R_{\mathrm{t}}$ is the threshold shear velocity ratio, $u_{* \mathrm{t} \mathrm{S}}$ is threshold friction velocity of the bare surface $\left(\mathrm{m} \mathrm{s}^{-1}\right), u_{* \mathrm{tR}}$ is the threshold wind friction velocity with roughness elements $\left(\mathrm{m} \mathrm{s}^{-1}\right), \sigma$ is the roughness element basal area to frontal area ratio, $\beta$ is the ratio of element to surface drag coefficients, and $m$ is an empirical constant ranging from 0 to 1 that accounts for the spatial heterogeneity of surface shear stress.

From a methodological perspective it is often impractical to monitor a surface for the onset of erosion as the threshold shear velocity is unlikely to remain constant with time. Consequently, it is necessary to consider the friction velocity ratio for a range of wind speeds and friction velocities, rather than for a single set of threshold conditions. Wolfe and Nickling (1996) proposed an alternative to the threshold friction velocity ratio $\left(R_{t}\right)$, which simply characterizes the ratio $(R)$ of the simultaneous shear velocities (or shear stresses) of the bare soil to a roughened surface, irrespective of threshold conditions. This generalizes Eq. 7 and in effect allows for the consideration of shear-stress partitioning between roughness and the intervening ground surface for all total stresses. In this experiment each of the variables in Eqs. 2 and 7 were known or measured as part of the experiment with the exception of the variables $c_{1}$, $c_{2}$ and $m$. Raupach et al. (1993) suggest that there is a limited range of values for the unmeasured variables of $c_{1}, c_{2}$ and $m$.

\section{Methodology}

In the spring of 2003 and 2004 field experiments were carried out at the Jornada Experimental Range (JER) of the U.S. Department of Agriculture near Las Cruces, New Mexico. A large barren area was selected within the JER locally known as the Scrape site (Gillette and Chen 2001) (total area $\approx 10,000 \mathrm{~m}^{2}$ ) because it possessed 


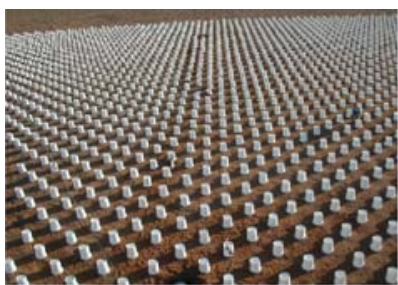

$\lambda=0.095$

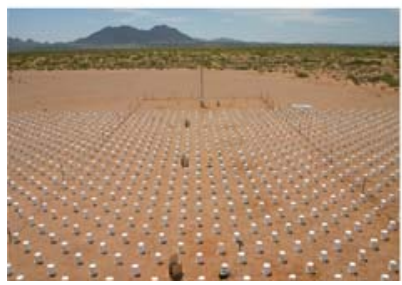

$\lambda=\mathbf{0 . 0 3 8}$

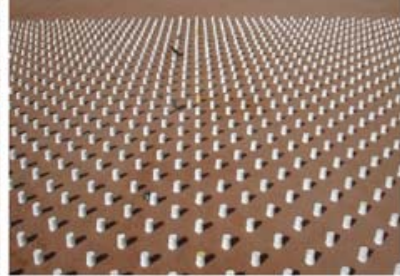

$\lambda=0.062$

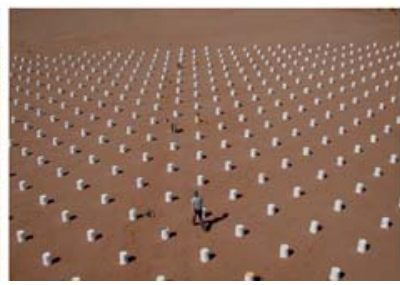

$\lambda=\mathbf{0 . 0 3 0}$

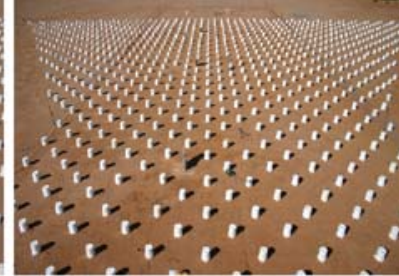

$\lambda=\mathbf{0 . 0 5 0}$

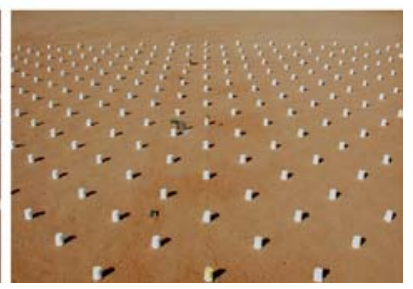

$\lambda=\mathbf{0 . 0 1 6}$

Fig. 1 Images of the six roughness arrays used in the experiments

several critical attributes. This particular site was of special interest because it provided (1) an extensive bare surface area, where a range of roughness configurations could be deployed without having to move locations, (2) an upwind fetch of $\approx 60 \mathrm{~m}$ of smooth surface for the prevailing wind direction before it would encounter the roughness array, (3) frequent wind of consistent direction, and (4) it provided a safe and secure environment for personnel and the scientific instruments at all times.

For this study, five-gallon plastic buckets $(0.26 \times 0.30 \times 0.36 \mathrm{~m})$ were used as the non-erodible roughness elements; the form of a bucket is a slightly tapering cylinder with the projected frontal area form being an isosceles trapezoid. In calculating $\lambda$, the frontal area of the bucket $\left(0.101 \mathrm{~m}^{2}\right)$ was used to represent the product of $b$ multiplied by $h(0.36 \mathrm{~m})$ in Eq. 2. Prior to use, each bucket was filled with two shovel scoops of sand and the lid secured to prevent the bucket from moving or falling over during high winds. The buckets were placed on the bare surface with the wide end (i.e., lid end) down in regular staggered arrays with varying $\lambda$ (Fig. 1 ). In each case, the roughness array was constructed in the form of an equilateral triangle with sides $60 \mathrm{~m}$ in length and the upwind side perpendicular to the expected dominant wind direction (Fig. 2). The position of each element in the array was determined by carefully marking the location in a grid defined by the intersection of 1.6- $\mathrm{mm}$ diameter steel cable that was tied between steel stakes that had been installed at the edge of the arrays at pre-measured distances, providing the proper inter-element spacing to achieve the target $\lambda$ values.

The length dimensions, number of elements, and roughness densities of the six test arrays are presented in Table 1. A roughness array was left in place until sufficient data were collected to characterize the aerodynamic properties of the surface, the shearstress partitioning associated with the array, and the drag force on the elements. Data were deemed acceptable for analysis only for airflow that entered and exited the array $20^{\circ}$ either side of the azimuth of the centreline of the array.

The $\tau$ generated by the wind was determined by estimating $u_{*}$ by fitting 10 -min average vertical wind speed profile data using least squares regression to the "law of 


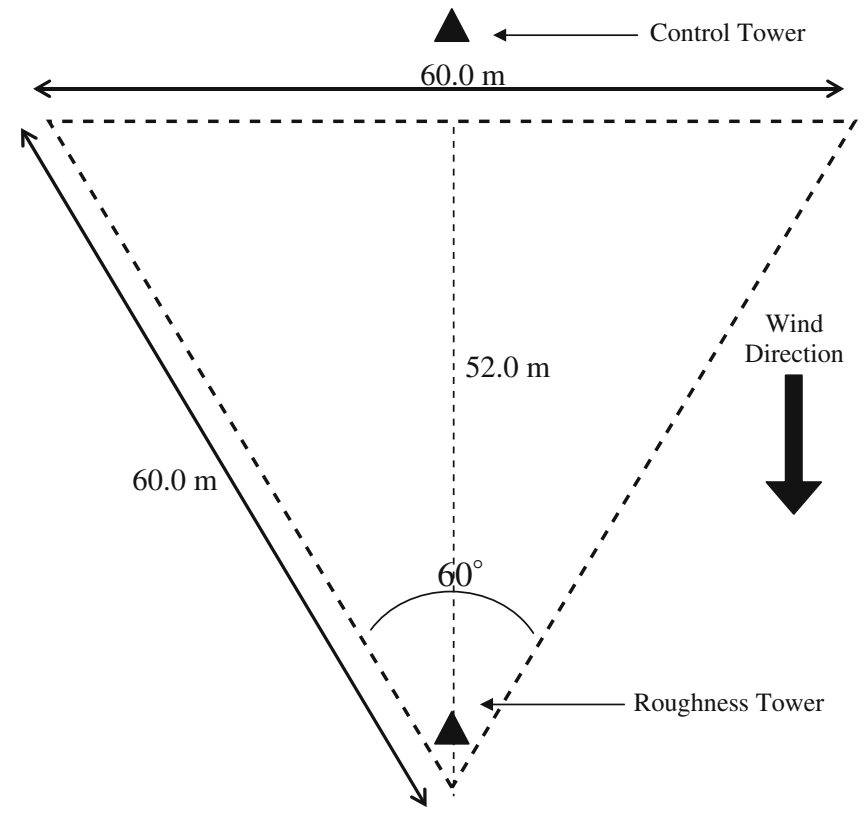

Fig. 2 The dimensions of the roughness arrays shown in Fig. 1

Table 1 The form characteristics of the roughness arrays and the position of the instruments in each roughness array

\begin{tabular}{|c|c|c|c|c|c|c|}
\hline Array characteristics & $\lambda=0.095$ & $\lambda=0.062$ & $\lambda=0.050$ & $\lambda=0.038$ & $\lambda=0.030$ & $\lambda=0.016$ \\
\hline $\begin{array}{l}\text { Spacing of roughness elements }(\mathrm{m}) \\
\text { (centre to centre of bucket } \\
\text { in the axial direction) }\end{array}$ & 1.424 & 1.800 & 2.060 & 2.300 & 2.548 & 3.300 \\
\hline $\begin{array}{l}\text { Number of roughness elements } \\
\text { Distance }(m) \text { from leading edge } \\
\text { of roughness to }\end{array}$ & 1775 & 1111 & 900 & 681 & 533 & 331 \\
\hline Irwin sensor position 1 & 47 & 48.00 & 45.93 & 47.20 & 46.02 & 47 \\
\hline Irwin sensor position 2 & & 37.20 & 38.35 & 37.95 & 38.23 & \\
\hline Irwin sensor position 3 & & 30.00 & 29.77 & 31.05 & 30.25 & \\
\hline Irwin sensor position 4 & & 22.45 & 21.65 & 21.85 & 22.65 & \\
\hline Irwin sensor position 5 & & 15.50 & 14.25 & 14.90 & 15.70 & \\
\hline Irwin sensor position 6 & & 8.20 & 7.96 & 8.00 & 7.76 & \\
\hline Drag balance 1 & 38 & 35.20 & 36.20 & 36.85 & 34.80 & 35 \\
\hline Drag balance 2 & & 20.70 & 20.00 & 20.45 & 19.40 & \\
\hline Drag balance 3 & & 6.25 & 6.02 & 6.45 & 6.30 & \\
\hline \multicolumn{7}{|l|}{$\begin{array}{l}\text { Distance }(m) \text { in front of leading } \\
\text { edge of roughness to }\end{array}$} \\
\hline $\begin{array}{l}\text { Control Instruments: Irwin sensor } \\
\text { and drag balance }\end{array}$ & 5 & 5.27 & 5.27 & 5.27 & 5.27 & 5 \\
\hline
\end{tabular}

the wall". The "law of the wall" is represented by the logarithmic wind speed profile observed in the ISL and can be written as

$$
\frac{u_{z}}{u_{*}}=\frac{1}{\kappa} \ln \left(\frac{z-d}{z_{\mathrm{o}}}\right)
$$


where $z_{\mathrm{o}}$ is the aerodynamic roughness length $(\mathrm{m}) ; z_{\mathrm{o}}$ is calculated from the slope and intercept values obtained from the least squares regression as $z_{\mathrm{O}}=\exp (-1 \times$ (slope/intercept)) for each 10-min average vertical wind speed profile, and $d$ is displacement height $(\mathrm{m})$. In practice, surfaces with large roughness elements require the addition of the displacement height in the logarithmic profile equation, which displacement height represents the upward displacement of the mean momentum sink (Jackson 1981). Both $z_{\mathrm{o}}$ and $d$ vary as a function of the height, spacing, shape of the elements (and in the case of vegetation its flexibility as well), the wind direction and wind speed, due to the local elevation changes created by the roughness elements (Finnigan 1979; Thom 1971). For surfaces with small roughness elements, $d=0$ when $d<<2 \mathrm{~m}$.

Vertical profiles of wind speed were measured with arrays of eight logarithmically spaced cup anemometers mounted on 1-m long boom arms on two 9-m high towers. The heights of the anemometers above the base of the tower (i.e., $0.50 \mathrm{~m}$, $0.87 \mathrm{~m}, 1.17 \mathrm{~m}, 1.73 \mathrm{~m}, 2.61 \mathrm{~m}, 3.96 \mathrm{~m}, 5.98 \mathrm{~m}, 9.00 \mathrm{~m}$ ) were identical for both towers. One tower was located near the apex of the roughness array and the other was placed outside the array (i.e., upwind) to measure the wind speed profile over the bare surface that was unaffected by the roughness elements (Fig. 2). Wind direction measurements were collected using wind vanes mounted on both anemometer towers at $9 \mathrm{~m}$. Estimates of $\tau$ were determined for both towers using Eq. 3.

An additional consideration that must be taken into account when using wind profile data for calculating $u_{*}$ is the height of the roughness sublayer (Raupach et al. 1980). According to Raupach et al. (1980), only wind speed measurements above the roughness sublayer $\left(z_{\mathrm{w}}\right)$ should be used to estimate the aerodynamic properties of the surface and the total shear stress (i.e., using Eq. 3). Raupach et al. (1980) derived their characterization of $z_{\mathrm{w}}$ from vegetated surfaces, finding Eq. 8 was not valid in this region. Cheng and Castro (2002) argue, however, that over roughness that is solid and regular in its distribution (similar to that used in this study) the flow below $z_{\mathrm{w}}$ can be characterized by the wind relationship found in the ISL if spatial averaging of wind speed is carried out, unlike the flow over vegetated surfaces. Although we could not carry out special averaging of wind speed, we adopt Cheng and Castro's (2002) approach and calculate $\tau$ from wind profiles that include the lowest anemometer, which may be at a level below $z_{\mathrm{w}}$. Evidence to support this assumption is presented in the results section. The wind data from the meteorological towers were also used to calculate the drag coefficient for the upwind surface $\left(C d_{\mathrm{S}}\right)$ and the six roughness arrays $\left(C d_{\mathrm{r}}\right)$ using Eq. 4.

Shear stress on the surface within an array was measured with Irwin sensors (Fig. 3), each sensor being a simple, omni-directional skin friction meter that measures the near-surface vertical pressure gradient (Irwin 1980). The differential in dynamic pressure is measured between two ports, one at the surface and the other at a height of $1.75 \mathrm{~mm}$ above the surface (Fig. 3). Once calibrated, the Irwin sensor can be used to measure surface shear stresses at frequencies greater than $10 \mathrm{~Hz}$ (Irwin 1980; Wu and Stathopoulos 1994) and has been used successfully in a variety of flow conditions and surface roughness configurations (Irwin 1980; Wu and Stathopoulos 1994, Monteiro and Viegas 1996; Crawley and Nickling 2003).

An example of the relationship between the output from an Irwin sensor and $\tau$ estimated from the vertical wind speed gradient (Eq. 8) from the upwind meteorological tower is shown in Fig. 4. The calibration equation is represented by the regression relationship estimated by the least squares method for 10-min average $\tau$ values and 


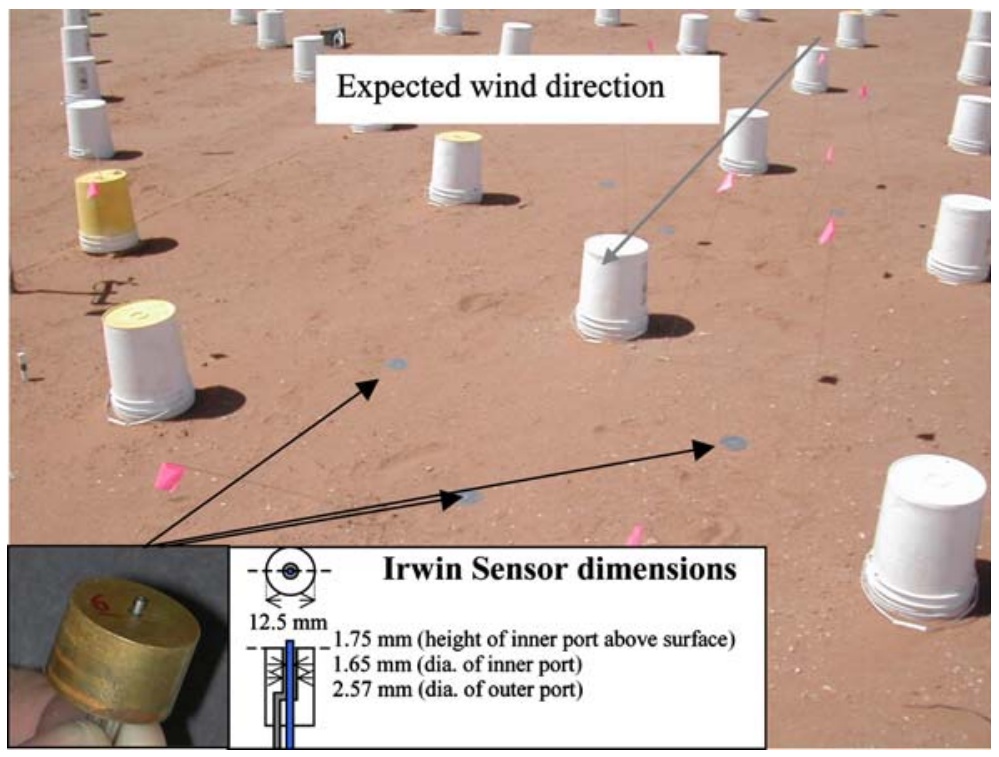

Fig. 3 The Irwin sensor placement among the roughness elements, with the bronze sensing head (see inset) placed in the middle of a $76 \mathrm{~mm}$ PVC disk. The grey arrow shows the wind direction that would be parallel with the centreline azimuth of the array. The inset in the Figure shows an image of an Irwin sensor and its dimensions removed from its grey PVC mounting disk

the associated 10-min average $\mathrm{mV}$ output from the Irwin sensor pressure transducer. A calibration relationship between an Irwin sensor external to the roughness array (inset into the surface in front of the meteorological tower upwind of the roughness) was established for each measurement period when the wind was of sufficient strength (i.e., wind speed at $9 \mathrm{~m}>6 \mathrm{~m} \mathrm{~s}^{-1}$ ) and approached the roughness array within $20^{\circ}$ either side of the azimuth of the centreline of the roughness array. The application of the calibration relationship to all Irwin sensors is based on previous field and laboratory experience and the assumption that since each pressure transducer is of the same manufacture and precision (ThermBrandt Ltd., $12 \mathrm{~mm}$ differential pressure transducer; Model DPT 32S12-0.5; precision $\pm 0.25 \%$ full scale) that a single calibration can be applied to all sensors.

Groups of two or three sensors were placed within the roughness array in an equidistant spacing down the centreline (Fig. 1), and the configurations at each measurement location and the roughness element spacing to Irwin length ratios were conserved for each of the arrays. The positions of the Irwin sensor groups within the roughness arrays are given in Table 1, and their relationships with the other instruments in the array are shown in Fig. 5.

The drag force on individual elements $(F)$ at three locations within the array and one position external to the array (i.e., upwind of the array) was measured using drag balances to which buckets were fixed. The drag balance is shown in Fig. 6. The principle of operation is based on measuring the force applied on the element by the wind that is transferred via a lever arm to a sensitive load cell fixed on one end to an immovable post and on the other end to the lever arm (see inset, Fig. 6). The lever arm and load cell were configured such that a force applied to the element would compress 


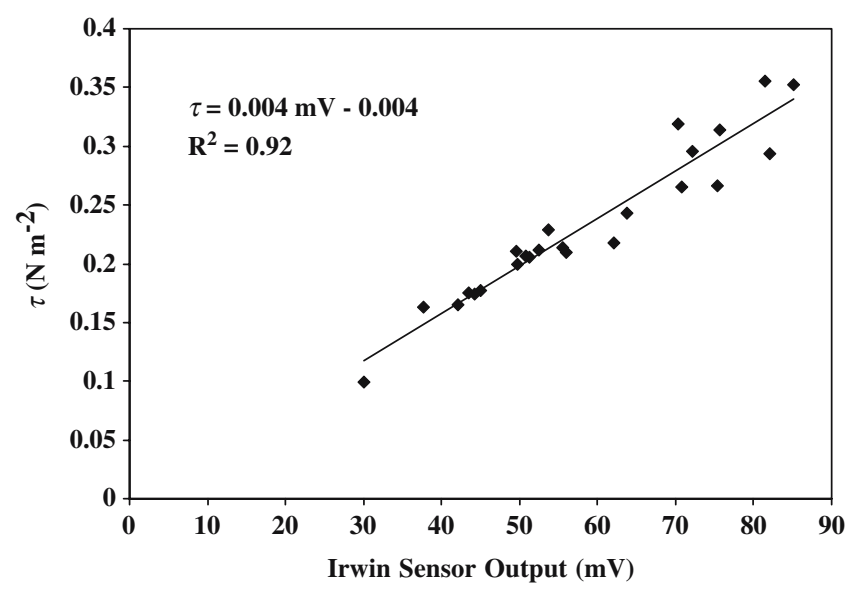

Fig. 4 An example of the relationship between $\tau$ estimated from the vertical wind speed profile using Eqs. 5 and 7 and $\mathrm{mV}$ output from the Irwin sensor located exterior and upwind of a roughness array

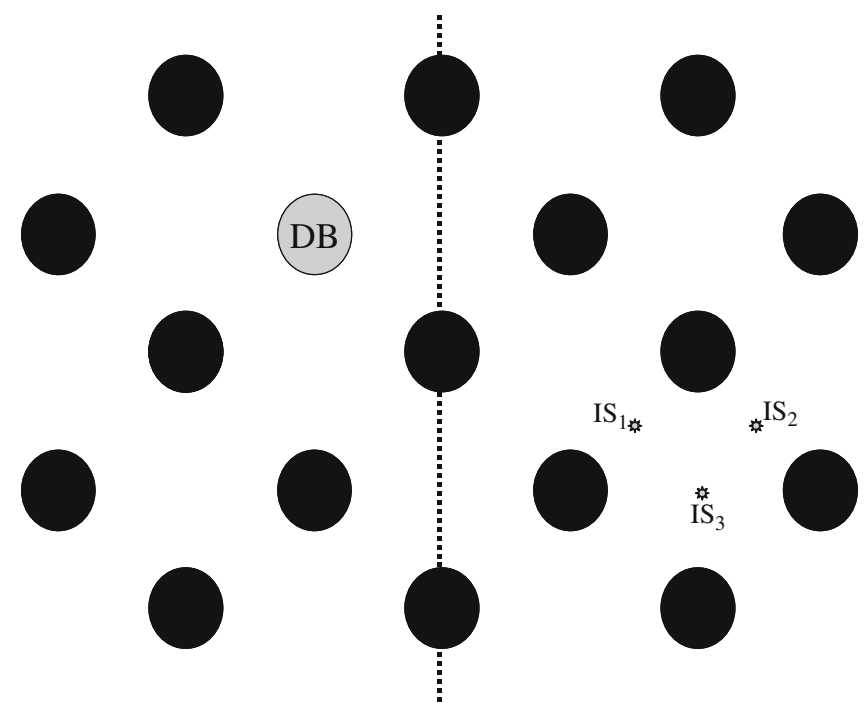

Fig. 5 Typical instrument position at a measurement location within a roughness array. IS indicates the position of an Irwin Sensor and DB the position of a drag balance in relation to the roughness elements. Relative positions of the instruments to the elements were identical for all arrays

the load cell. The instrument is calibrated on a bench by hanging a series of weights from the point where the roughness element is fixed to the lever arm to establish the force versus output relationship. To account for wind approach angles that are not perpendicular to the front face of the roughness element, calibration relationships are developed for $5^{\circ}$ intervals either side of the centreline of the element. An example of the calibration relationships for one of the force balances for a series of $5^{\circ}$ intervals is shown in Fig. 7 and is typical of the other three used in 2004. It should be noted that an earlier version of this design was used in 2003, which did not have the same sensitivity as the version used in 2004 (described above). 


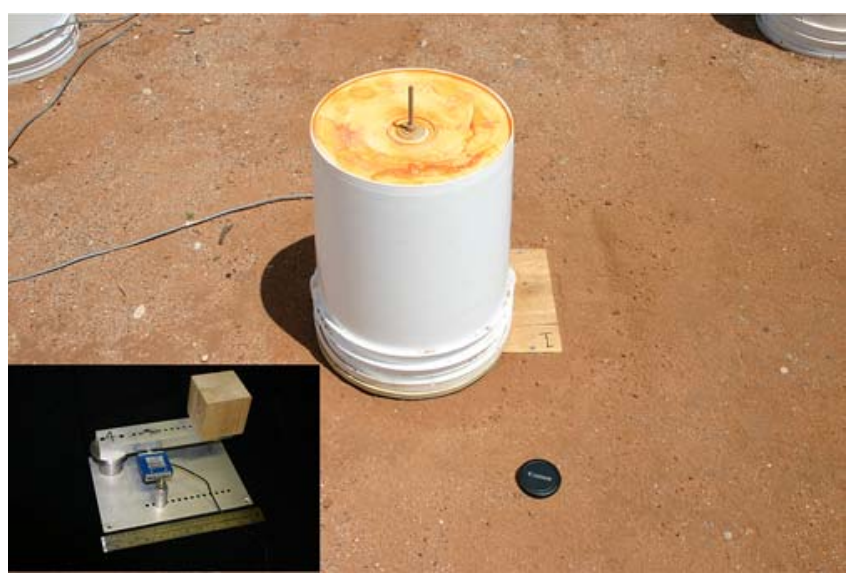

Fig. 6 The drag balance mechanism (inset bottom left corner) and as it was configured for the Jornada experiments. The mechanism is in a box directly below the roughness element and the element is coupled to the lever arm by a threaded rod passing through the bucket and secured to the arm with a nut (the wooden block seen in the inset represents a generic roughness element)

The drag balances were sealed inside boxes and installed in the roughness array by burying the box and leaving the top flush with the surface. A hole in the top of the box provided access to the attachment point for the roughness elements to the lever arm. The buckets were fixed to the lever arms using a threaded rod that passed through the centre of the bucket and fastened with a washer and nut (Fig. 6) locking the bucket to the drag balance lever arm. After attachment, the bottom of the bucket was slightly elevated above the surface $(\approx 3 \mathrm{~mm})$ to prevent contact and allowing it free movement. The positions of the drag balances within each roughness configuration are identified in Table 1 and their relationship with the other instruments in the array shown in Fig. 5. A drag balance with its attached bucket was placed into a row of roughness elements replacing one of the elements in the row.

Typical force versus wind speed squared relationships for roughness elements located within and outside (i.e., upwind) of the array for $\lambda=0.05$ are shown in Fig. 8 . In all measurement cases, the relationships are well described by linear functions with $R^{2}$ values $>0.88$. Adjacent to each drag balance, wind speed and direction were measured with a single anemometer/wind vane combination positioned at $0.5 \mathrm{~m}$ above the surface. The calibration equations for each measurement interval (60s) used to convert output to force in Newtons were applied based on the wind direction measured with the adjacent wind vane. The drag balances were used to measure the applied wind force on the elements within and upwind of the array, as well as their surface-mounted drag coefficients $\left(C d_{\mathrm{e}}\right)$ using Eq. 5 with the reference wind speed being $0.36 \mathrm{~m}$ (i.e., the height of the roughness element), which was obtained by extrapolating the measured wind speed versus height relationship.

\section{Results}

The data collected over the two field seasons resulted in nine periods for the six roughness arrays for which the wind direction was acceptable $\left(195-235^{\circ}\right)$ and for which the 

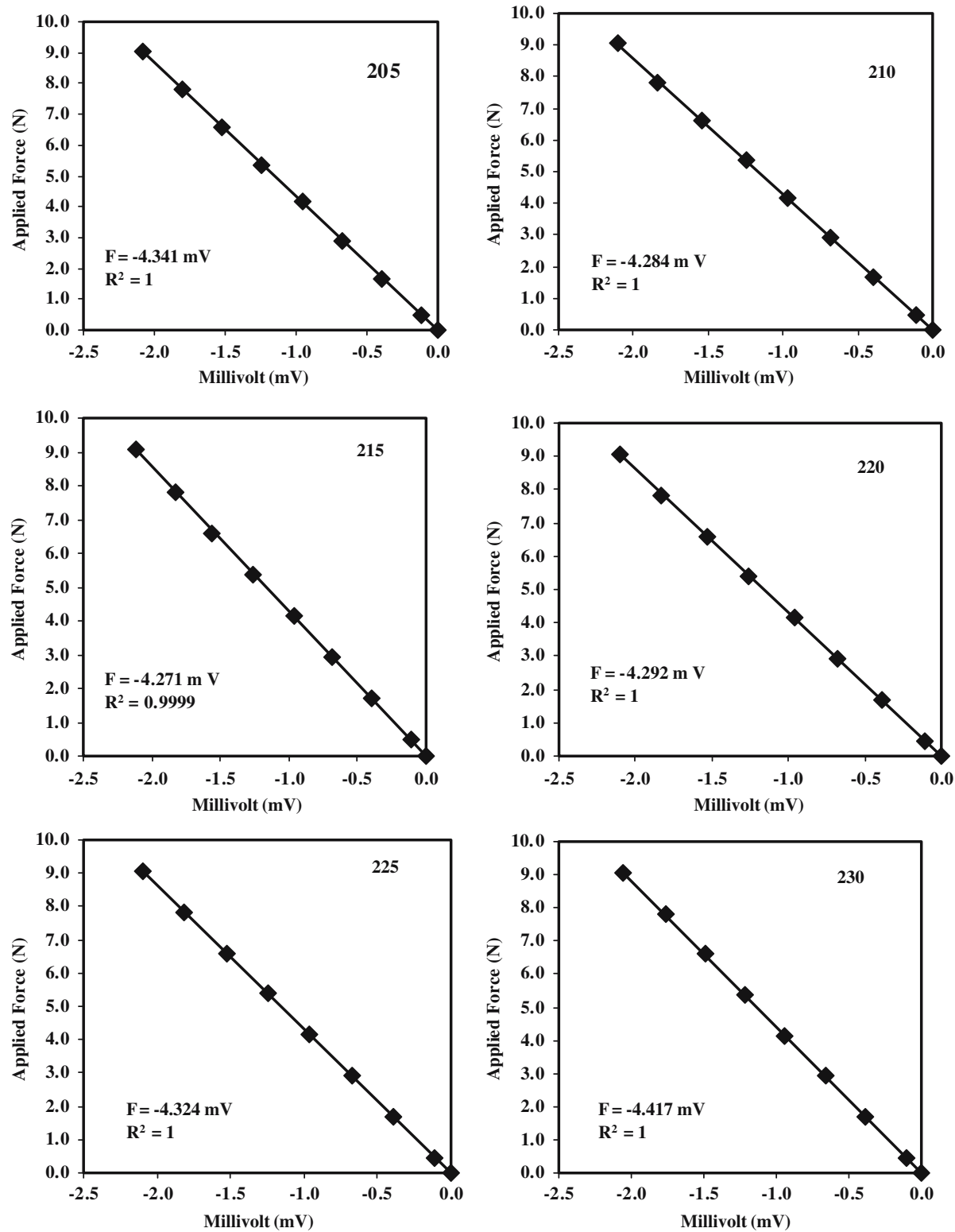

Fig. 7 Typical force versus $\mathrm{mV}$ relationships for $5^{\circ}$ intervals for the force balances used in 2004 . The number in the upper right hand corner is the wind direction the calibration equation was used for

fit of the law of the wall (Eq. 8) to the 10-min average wind profiles had $R^{2}$ values $>0.95$ (Table 2). In addition to the above, the dataset from May 1, $2004(\lambda=0.05)$ was also examined to extend the range of $\lambda$, despite the fact that these data did not completely satisfy the direction constraints applied to the other nine sampling periods. A discontinuous record within the stated start and stop times of the identified periods was the result of filtering the data by wind direction and goodness of fit to the "law of 


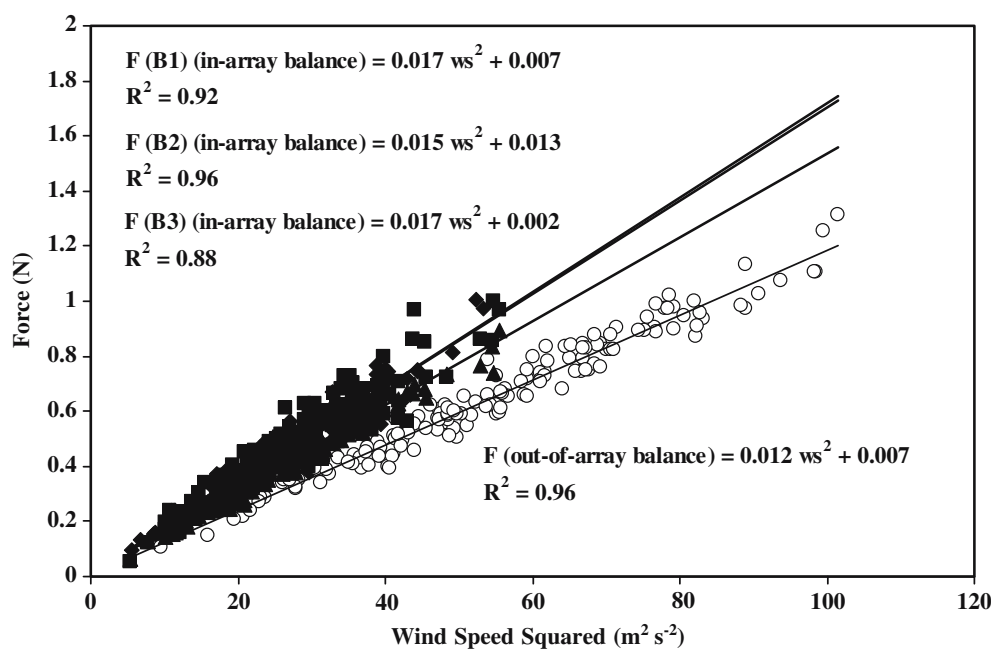

Fig. 8 Typical force versus wind speed squared relationships measured with the four force balances measured during the $\lambda=0.05$ array set-up. Force balance 1 is represented by the solid black diamonds, force balance 2 by the solid black triangles, force balance 3 by the solid black squares and the out-of-array balance by the open circles

Table 2 The dates, duration, and wind speed and direction conditions for the measurement periods

\begin{tabular}{lllllll}
\hline Date & Start time & Stop time & No. obs. ${ }^{\mathrm{b}}$ & $\lambda$ & $\begin{array}{l}\text { Mean 9-m } \\
\text { wind speed } \\
\left(\mathrm{m} \mathrm{s}^{-1}\right)\end{array}$ & $\begin{array}{l}\text { Mean 9-m } \\
\text { wind direction } \\
(\text { degrees })\end{array}$ \\
\hline 31 May 2003 & 0800 & 1610 & 46 & 0.016 & $2.68( \pm 1.51)^{\mathrm{b}}$ & $235( \pm 31)$ \\
23 May 2004 & 1030 & 1400 & 22 & 0.030 & $9.00( \pm 1.08)$ & $235( \pm 6)$ \\
30 April 2004 & 1020 & 2310 & 78 & 0.038 & $9.57( \pm 1.61)$ & $216( \pm 12)$ \\
01 May 2004 & 1240 & 2020 & 47 & 0.038 & $6.35( \pm 1.84)$ & $280( \pm 27)$ \\
12 May 2004 & 0940 & 1620 & 30 & 0.050 & $8.16( \pm 1.02)$ & $230( \pm 6)$ \\
13 May 2004 & 0940 & 2000 & 25 & 0.050 & $6.95( \pm 1.44)$ & $227( \pm 4)$ \\
22 April 2004 & 1300 & 1650 & 25 & 0.062 & $10.08( \pm 1.33)$ & $236( \pm 10)$ \\
23 April 2004 & 1240 & 1920 & 37 & 0.062 & $9.30( \pm 1.01)$ & $232( \pm 7)$ \\
01 May 2003 & 1050 & 1900 & 37 & 0.095 & $7.07( \pm 2.33)$ & $220( \pm 9)$ \\
05 May 2003 & 1200 & 1910 & 39 & 0.095 & $9.14( \pm 1.57)$ & $221( \pm 9)$ \\
\hline
\end{tabular}

a Local Time

b i.e., the number of valid 10-min observations in the monitoring period

c Number in brackets is the standard deviation of the mean in the column

the wall" for the wind profile. The wind speed profiles that met our filtering criteria represented conditions with vigorous surface winds often associated with periods of sediment transport (Gillies et al. 2006). Although vertical temperature profiles were not measured during these periods Richardson numbers are typically near zero (Gillette et al. 1978). Recent measurements by Gillette et al. (2006) at the JER in close proximity to the Scrape site also confirm that under these conditions the Richardson number is close to zero. Due to instrument failure, there are several tests in which only Irwin sensor or force balance data were available. 


\subsection{Surface aerodynamic properties}

The roughness element arrays in this experiment cause a step change in roughness from smooth to rough and an associated change in $z_{\mathrm{o}}$. In comparing the wind stress conditions upwind and downwind of the arrays, the measurements taken at the downwind edge are assumed to be in the equilibrium layer created by the introduced roughness. We make this assumption based on the strong linear profiles of wind speed versus natural logarithm of height measured at the tower near the downwind edge of the roughness, which do not exhibit any discontinuity throughout the measurement region $(0.5-9.0 \mathrm{~m})$, providing confidence that the measured profiles are within an internal boundary layer (IBL) (Garratt 1990), and that the wind speed data at $0.5 \mathrm{~m}$ is not noticeably perturbed by strongly inhomogeneous roughness sublayer flow. For a few select profiles we eliminated the 9.0-m wind speed and re-analysed the data and found within the measure of uncertainty for $z_{\mathrm{o}}$ no discernable difference.

Garratt (1990) has cautioned that far downstream of the leading edge of a step change in roughness, in neutral conditions, the inner equilibrium layer is characterized by a logarithmic profile form, although the logarithmic form of the wind profile does not depend on the assumption of constant flux. We present data below that lend support to our assumption that the wind profile measurements at the trailing edge of the roughness are sufficient for estimating total shear stress and allow characterization of the aerodynamic properties of the rough surfaces.

\subsubsection{Aerodynamic roughness length and displacement height}

The mean aerodynamic roughness lengths $\left(z_{\mathrm{o}}\right)$ and their associated standard deviations are presented in Table 3; the $z_{\mathrm{o}}$ values associated with the wind profiles upwind of the arrays ranged from 0.00018 to $0.00158 \mathrm{~m}$. In contrast, the $z_{\mathrm{O}}$ values associated with the roughness array surfaces ranged from 0.00218 to $0.02216 \mathrm{~m}$. This systematic increase of $z_{\mathrm{o}}$ with increasing $\lambda$ has been observed in other field experiments (e.g., Kutzbach 1961; Lettau 1969) and wind-tunnel studies (e.g., Marshall 1971; Raupach et al. 1980). A comparison of the dimensionless roughness length $\left(z_{\mathrm{o}} / h\right.$, where $h$ is element height) for the Jornada field data with the empirical curve of Lettau (1969) and the modelled relationship of Raupach et al. (1993) is shown in Fig. 9. In general, the Jornada data are in close agreement with the Lettau and Raupach relationships for the observed range of $\lambda$, although the field data fall somewhat below the theoretical curve of Raupach et al. (1993).

Wooding et al. (1973) suggested that the relationship between $z_{\mathrm{o}}$ and $\lambda$ is better defined if the inter-element spacing length in the streamwise direction $(l)$ is included as a second length scale for the roughness elements through the relationship

$$
\frac{z_{0}}{h}=\lambda\left(\frac{h}{l}\right)^{0.4}
$$

where $l$ is the streamwise inter-element spacing $(\mathrm{m})$.

The change in $z_{\mathrm{o}} / h$ and the Wooding et al. (1973) parameter (Eq. 9) for the $\lambda$ values used at Jornada are shown in Fig. 10. Although there is a slight improvement in the relationship between $\lambda$ and $z_{\mathrm{o}} / h$ with the inclusion of the inter-element spacing length scale, it does not appear to be significant in this case when one considers the scatter associated with $z_{\mathrm{o}}$ in the field data (Table 3). 
Table 3 Mean aerodynamic roughness lengths and their associated standard deviations and coefficient of variation for the smooth upwind surface and the six roughness arrays

\begin{tabular}{llllllll}
\hline Date & $\lambda$ & \multicolumn{2}{c}{ Smooth upwind surface } & \multirow{2}{*}{$\mathrm{cv}$} & \multicolumn{2}{l}{ Rough surface } & \multirow{2}{*}{$\mathrm{cv}$} \\
\cline { 3 - 4 } & & $z_{\mathrm{o}}(\mathrm{m})$ & $\mathrm{SD}(\mathrm{m})$ & & $z_{\mathrm{o}}(\mathrm{m})$ & $\mathrm{SD}(\mathrm{m})$ & \\
\hline 31 May 2003 & 0.016 & 0.00324 & 0.00958 & 2.96 & 0.00218 & 0.00286 & 1.31 \\
23 May 2004 & 0.030 & 0.00018 & 0.00004 & 0.20 & 0.00279 & 0.00068 & 0.24 \\
30 April 2004 & 0.038 & 0.00088 & 0.00067 & 0.76 & 0.00873 & 0.00282 & 0.32 \\
01 May 2004 & 0.038 & 0.00046 & 0.00022 & 0.48 & 0.00537 & 0.00183 & 0.34 \\
12 May 2004 & 0.050 & 0.00044 & 0.00025 & 0.56 & 0.00813 & 0.00139 & 0.17 \\
13 May 2004 & 0.050 & 0.00051 & 0.00023 & 0.44 & 0.00948 & 0.00409 & 0.43 \\
22 April 2004 & 0.062 & 0.00121 & 0.00032 & 0.26 & 0.01083 & 0.00199 & 0.18 \\
23 April 2004 & 0.062 & 0.00158 & 0.00059 & 0.38 & 0.01304 & 0.00301 & 0.23 \\
01 May 2003 & 0.095 & 0.00123 & 0.01369 & 11.11 & 0.01796 & 0.01316 & 0.73 \\
05 May 2003 & 0.095 & 0.00022 & 0.00016 & 0.72 & 0.02216 & 0.00831 & 0.38 \\
\hline
\end{tabular}

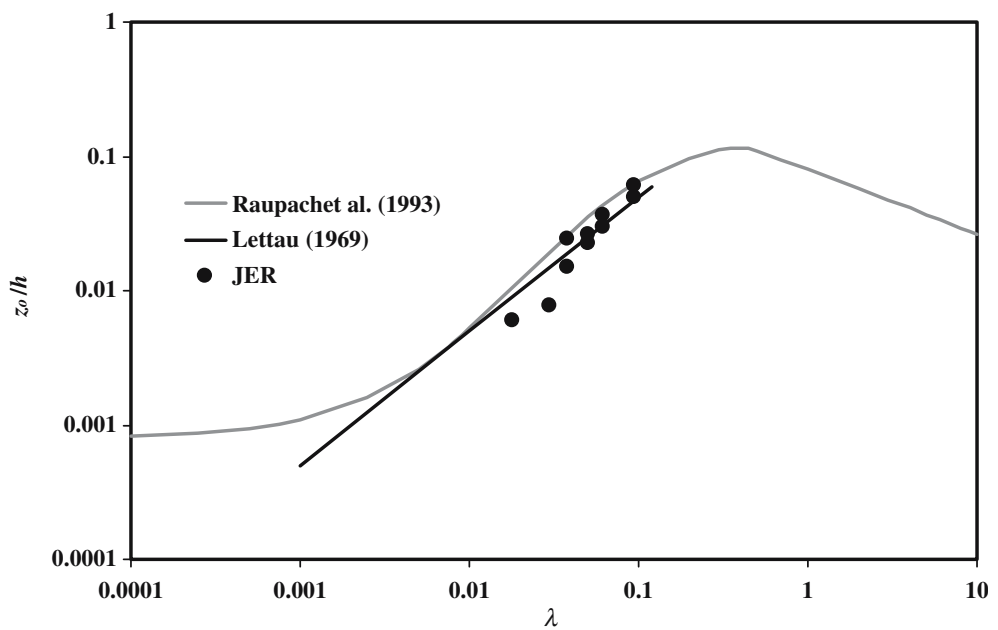

Fig. 9 The relationship between dimensionless aerodynamic roughness length $\left(z_{\mathrm{o}} / h\right)$ and $\lambda$ for the six roughness arrays measured at Jornada (JER) and compared with the modelled relationships of Lettau (1969) and Raupach et al. (1993) (defined by Eq. 7)

Numerous studies have shown that when air encounters and flows over a rough surface the wind profile may be displaced upwards requiring the addition of a displacement height term $(d)$ in the Prandtl-von Karman equation (i.e., Eq. 8). The presence of a displacement height was investigated for each surface roughness configuration using an iterative analysis procedure to obtain the best fit of the data to Eq. 9. For these Jornada data the procedure did not result in an appreciable improvement in the fit of the 10-min average wind profiles to the "law of the wall" and in many instances produced nonsensical values of $d$ (i.e., $d$ was negative). Consequently, we did not use a non-zero $d$ to calculate friction velocity from the vertical wind speed profiles.

Based on the relationship between $\lambda$ and $d$ presented in MacDonald et al. (1998, p. 1861), the displacement height for the least dense array should be $\approx 0.02 \mathrm{~m}$ and for the most dense array $\approx 0.07 \mathrm{~m}$. The small range of values for $d$ for these roughness arrays is also supported by the comparison shown between $z_{\mathrm{o}} / h$ and $\lambda$ in Fig. 8. If 


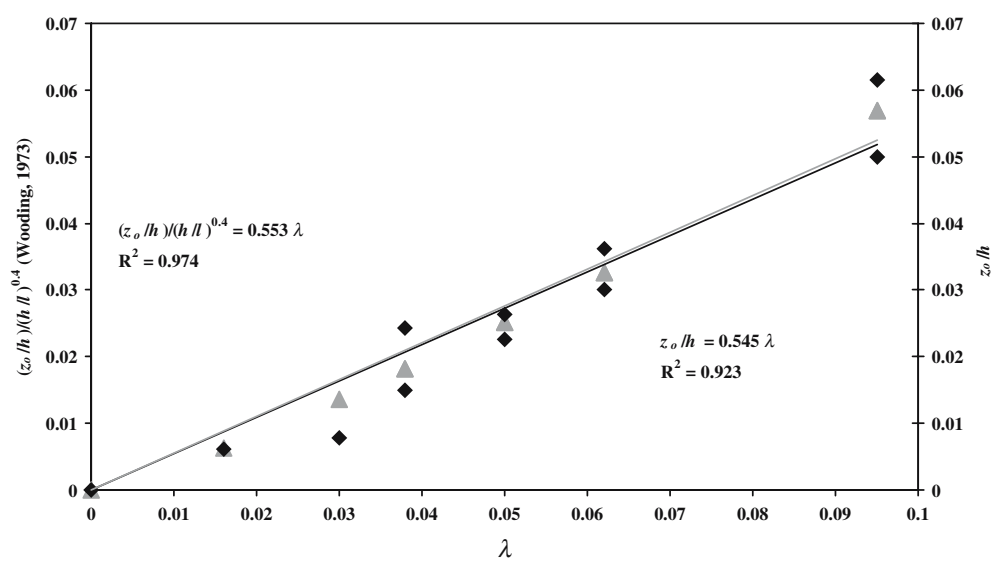

Fig. 10 The relationships between dimensionless aerodynamic roughness length $\left(z_{0} / h\right)$ (black diamonds) and as defined by Wooding (1973) (grey triangles) and $\lambda$ for the six roughness arrays

Table 4 Mean and standard deviation $(\mathrm{SD})$ values for the surface drag coefficients for the smooth $\left(C d_{\mathrm{S}}\right)$ and rough $\left(C d_{\mathrm{r}}\right)$ surfaces

\begin{tabular}{llllll}
\hline$\lambda$ & \multicolumn{2}{l}{$C d_{\mathrm{s}}$} & & \multicolumn{2}{l}{$C d_{\mathrm{r}}$} \\
\cline { 2 - 3 } & Mean & SD & & Mean & SD \\
\hline 0.016 & 0.0028 & 0.0029 & & 0.0055 & 0.0028 \\
0.030 & 0.0025 & 0.0003 & & 0.0067 & 0.0007 \\
0.038 & 0.0042 & 0.0011 & & 0.0117 & 0.0059 \\
0.050 & 0.0032 & 0.0006 & & 0.0115 & 0.0021 \\
0.062 & 0.0050 & 0.0007 & & 0.0138 & 0.0019 \\
0.095 & 0.0020 & 0.0021 & & 0.0153 & 0.0233 \\
\hline
\end{tabular}

a displacement height of significant magnitude had been present these data would likely not have fallen as close to the line depicting the model values of Lettau (1969) or Raupach et al. (1993) as is observed. Although a displacement height was considered unnecessary to describe the wind speed profile for the range of $\lambda$ used in this experiment it may be required for more dense arrays.

\subsubsection{Drag coefficients of the smooth $\left(C d_{\mathrm{S}}\right)$ and rough $\left(C d_{\mathrm{r}}\right)$ surfaces}

The average surface drag coefficients for each of the roughness configurations for the surface upwind of the array, i.e., $C d_{\mathrm{S}}$ and the associated $C d_{\mathrm{r}}$ for the roughness arrays are listed in Table 4 . The $C d_{\mathrm{S}}$ and $C d_{\mathrm{r}}$ values were computed using Eq. 4 with $z=0.36 \mathrm{~m}$ as the reference height (i.e., height of the buckets) for each 10-min sampling period and then averaged to obtain a mean value for the given roughness array. As expected, the $C d_{\mathrm{S}}$ values for the surface upwind of the roughness arrays were relatively constant and had an average value of $0.0033( \pm 0.0011)$. In contrast the $C d_{\mathrm{r}}$ values for the roughness arrays increased with increasing $\lambda$ and ranged from 0.006 to 0.015 for $\lambda=0.016$ and 0.095 , respectively (Table 4 ). A positive linear relationship was observed between the ratio $C d_{\mathrm{r}}: C d_{\mathrm{S}}$ with increasing $\lambda$ (Fig. 11 ), $C d_{\mathrm{r}}$ was normalized by the average value of $C d_{\mathrm{S}}$ for all available 10-min data and the regression was forced through 1 , since for $\lambda=0$ the ratio should tend to 1 . 


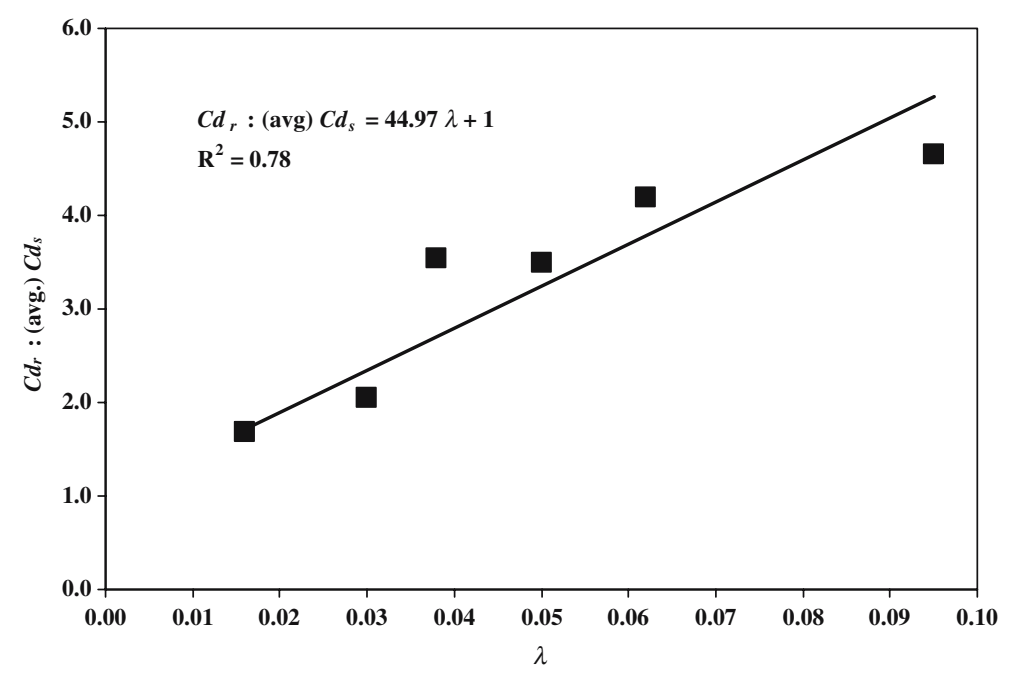

Fig. 11 The relationship between the ratio of $C d_{\mathrm{r}}: C d_{\mathrm{S}}$ and $\lambda$ with the intercept forced through 1 as this ratio should approach one as the roughness becomes more sparse

\subsection{Element drag force and $C d_{\mathrm{e}}$ relationships}

The drag force on the roughness elements was observed to change as a function of downwind distance in the roughness array and as a function of $\lambda$. These data are only available for the 2004 measurement periods as insufficient numbers of drag balances were available in 2003 to characterize the spatial variability. To compare this relationship among the four arrays $(\lambda=0.062,0.050,0.038$, and 0.030$)$ tested in 2004 the drag force measurements of the interior array elements were normalized to the drag force on the element upwind of the array. The change in normalized element drag force as a function of normalized downwind distance (NDD) is shown in Fig. 12. NDD is expressed as the ratio of the distance upwind or downwind of the leading edge of the roughness array divided by the element height (i.e., NDD $=x / h$ ), noting that the distance downwind of the leading edge of the roughness is expressed as a negative value. The positions of the drag balances changed between the four $\lambda$ configurations due to changes in row spacing so the NDD designated positions of the drag balances differ slightly between different $\lambda$ (Table 1 ).

The change in normalized element drag (NED) as a function of NDD is best described by an exponential function of the form NED $=a \mathrm{e}^{(b \mathrm{NDD})}$ (Fig. 12) where the rate of change of force on a roughness element as a function of downwind distance in the array is characterized by the $b$ coefficient. In Fig. 13, the $b$ coefficient is plotted as a function of $\lambda$. The observed relationship indicates that $\lambda$ affects the rate at which the drag force on the roughness elements adjusts to the roughness configuration. The denser the roughness array, the greater the distance that is required to reach equilibrium conditions of force on the elements. It is important to note that for the $\lambda=0.03$ array, there is essentially no measurable change in NED as a function of NDD or the force measured on the isolated roughness element outside the array (Fig. 12).

The effect of $\lambda$ on NED can also be demonstrated by comparing the data for the NED from the drag balances that were NDD $\approx-100$ from the leading edge of the 

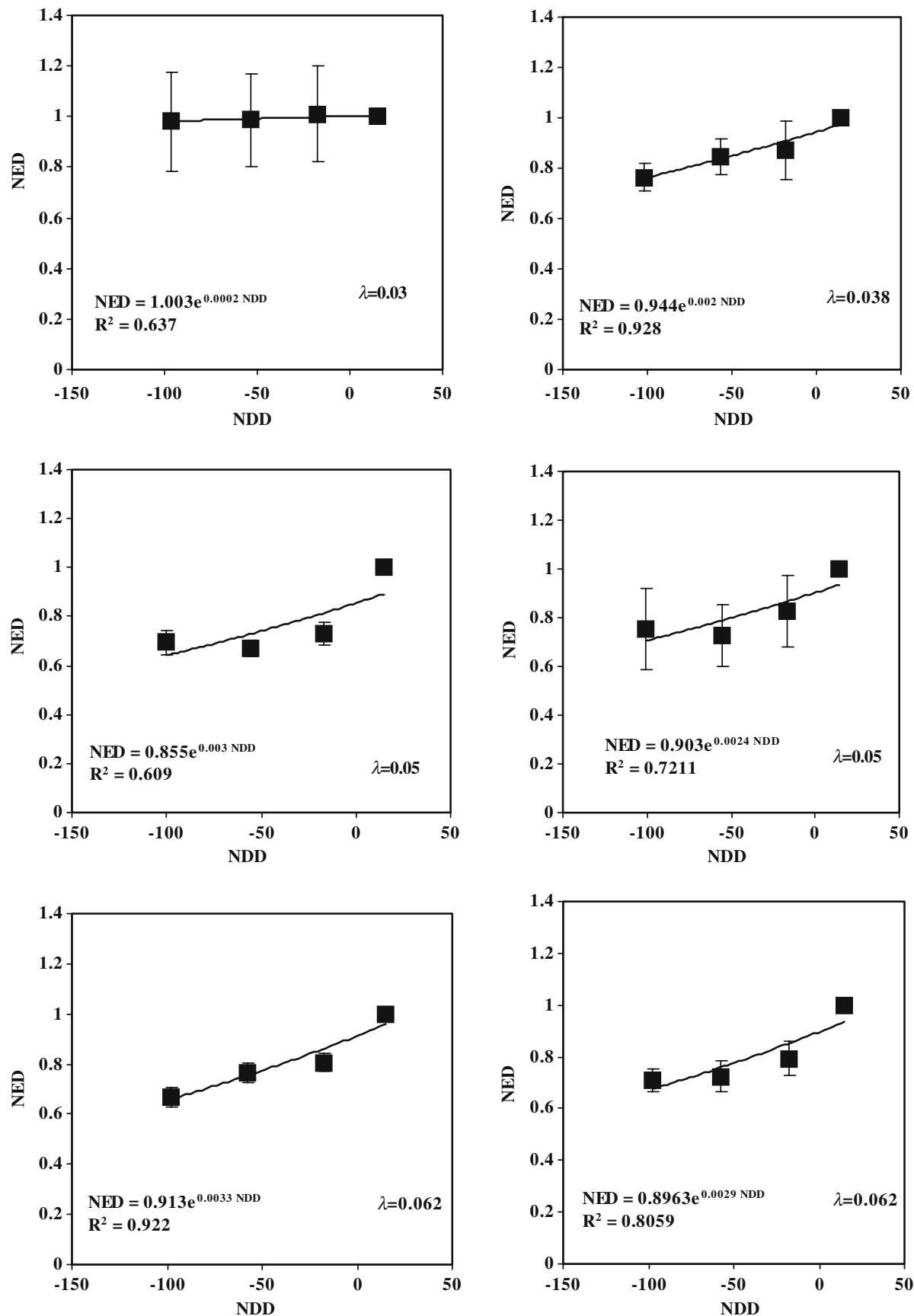

Fig. 12 The relationship between NED and NDD for the four roughness arrays used in 2004. Error bars indicate the standard deviation on the mean values for the available 10-min mean values 


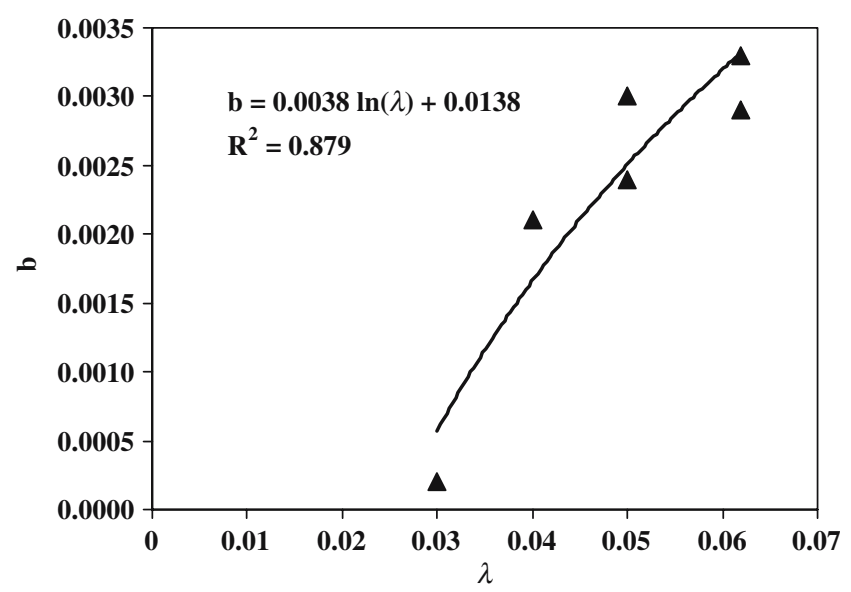

Fig. 13 The relationship between the $\mathrm{b}$ coefficient in the $\mathrm{NED}=a \mathrm{e}^{(b \mathrm{NDD})}$ and $\lambda$ from the four arrays measured in 2004, showing the rate of change of force on the elements scales as a function of roughness density

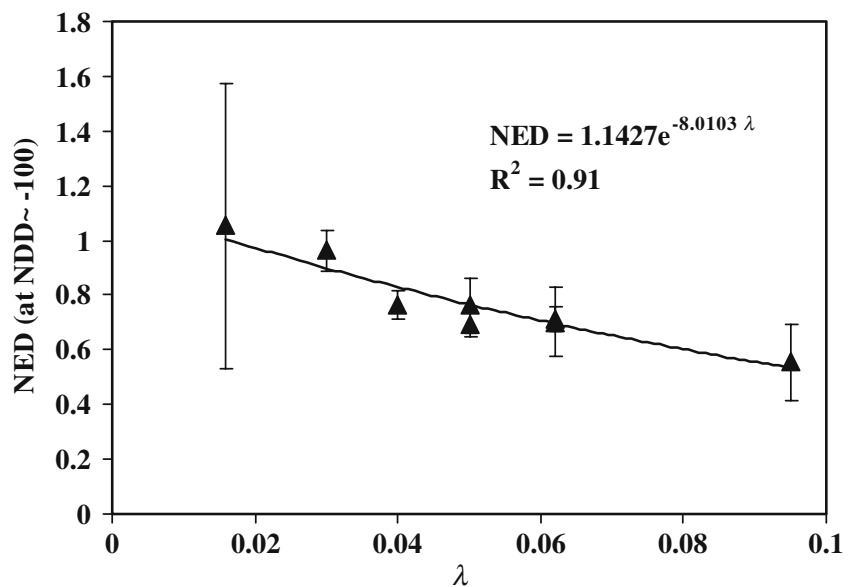

Fig. 14 The relationship between NED near the downwind edge of the roughness (NDD $\approx-100$ ) and $\lambda$. The data suggests at $\lambda \leq 0.038$ the individual force on the elements near the trailing edge of the array is similar to an element external to the array and unaffected by the population of roughness elements in the array

roughness, including the data for the 0.095 and 0.016 arrays (Fig. 14) as a function of $\lambda$. For these data, an exponential decrease in the force on the roughness elements near the downwind edge of the array as roughness density increases is observed (Fig. 14). The data presented in Fig. 14 also suggests that at $\lambda$ somewhere between 0.04 and 0.03 the individual force on the elements near the trailing edge of the array is similar to an element external to the array and unaffected by the population of roughness elements in the array. This could, however, be a reflection of the sensitivity limits of the drag balances to resolve differences in applied force.

The mean and standard deviation for the $C d_{\mathrm{e}}$ for the out-of-array element for each of the six roughness configurations was 0.19 and 0.07 , respectively. These values were 
based on 12801 -min averages. In comparison, Taylor (1988) reported a $C d_{\mathrm{e}}$ of 0.19 for a solid cylinder. The Reynolds number $(R e)$ defined by

$$
R e=\frac{\rho_{\mathrm{a}} u_{z} h}{\mu},
$$

where $\mu$ is the molecular viscosity $\left(\mathrm{N} \mathrm{s} \mathrm{m}^{-2}\right)$ was in all cases $>50,000$, making $C d_{\mathrm{e}}$ independent of $R e$.

\subsection{Surface shear stress $\left(\tau_{\mathrm{S}}\right)$}

The shear stress at the surface $\left(\tau_{\mathrm{S}}\right)$ in each of the roughness arrays was measured with groups of Irwin sensors (two to three per group) located at six positions in the roughness arrays (Table 1$)$. The Irwin sensor-derived $\tau_{\mathrm{S}}$ at each location normalized to the out of array $\tau$ (also Irwin sensor-derived) essentially represents a localized average shear stress ratio $\left(R_{1}\right)$ value for each sampling location. When the localized $R_{1}$ values are plotted as a function of NDD for the four roughness arrays measured in 2004 (Fig. 15) there is a consistent pattern of decreased surface shear stress at the first point of measurement $(\mathrm{NDD} \approx-22$ ) followed by a further decrease at NDD $\approx-42$, then a step increase that recovers (to within the measurement uncertainty) to the level measured at NDD $\approx-22$. Previous work by Rao et al. (1974) and Panofsky and Townsend (1964) suggests that that there is a rapid decrease in $\tau_{\mathrm{S}}$ as airflow makes a sharp transition from a smooth to a rough surface. This pattern of decreased $\tau_{\mathrm{S}}$ near $\mathrm{NDD} \approx-42$ followed by recovery to a greater value past this position in the arrays is observed for all but the $\lambda=0.03$ array, which shows an increased amount of shear stress reduction at $\mathrm{NDD} \approx-63$. This however may have resulted from the relatively small size of this dataset.

The pattern for the three denser roughness arrays suggests that element height is the dominant control on the location of this zone of increased shear stress reduction, as it occurs in the same position regardless of the number of rows of elements upwind of this location. This pattern of a minimum surface shear stress at NDD $\approx-42$ is consistent for both the average of the sensors at each measurement location and when comparing the individual sensors at the same relative position among the six Irwin clusters.

An example of this pattern for each Irwin sensor for each position down the array is shown in Fig. 16 for the $\lambda=0.062$ array. The difference in the amount of shear stress reduction among sensors in the same cluster reflects the degree to which they are sheltered in the zone of reduced shear behind the elements in front of them, as well as the wind direction. As was often the case for this experiment, the wind was shifted to the west of the centerline of the array. Because of this wind shift, the sensors on the easterly (left) side of an Irwin sensor cluster experience a greater amount of shear stress reduction due to increased sheltering in the lee of the roughness (refer to Fig. 5). Regardless of wind direction and Irwin sensor position (left, middle, or right), there is a zone of increased reduction in shear stress at NDD $\approx-42$ that is clearly expressed in the Irwin sensor data. Unfortunately, it was not possible to observe this pattern in the 2003 datasets because of the different positions of the instruments in 2003. In 2003, the second instrument cluster was located at NDD $<-60$, which is beyond the zone of the shear stress minimum observed in the other arrays.

The data from the Irwin sensors were also used to estimate the average shear-stress partitioning ratio $(R)$ for each of the roughness arrays. For each 10-min average within 䈝 Springer 

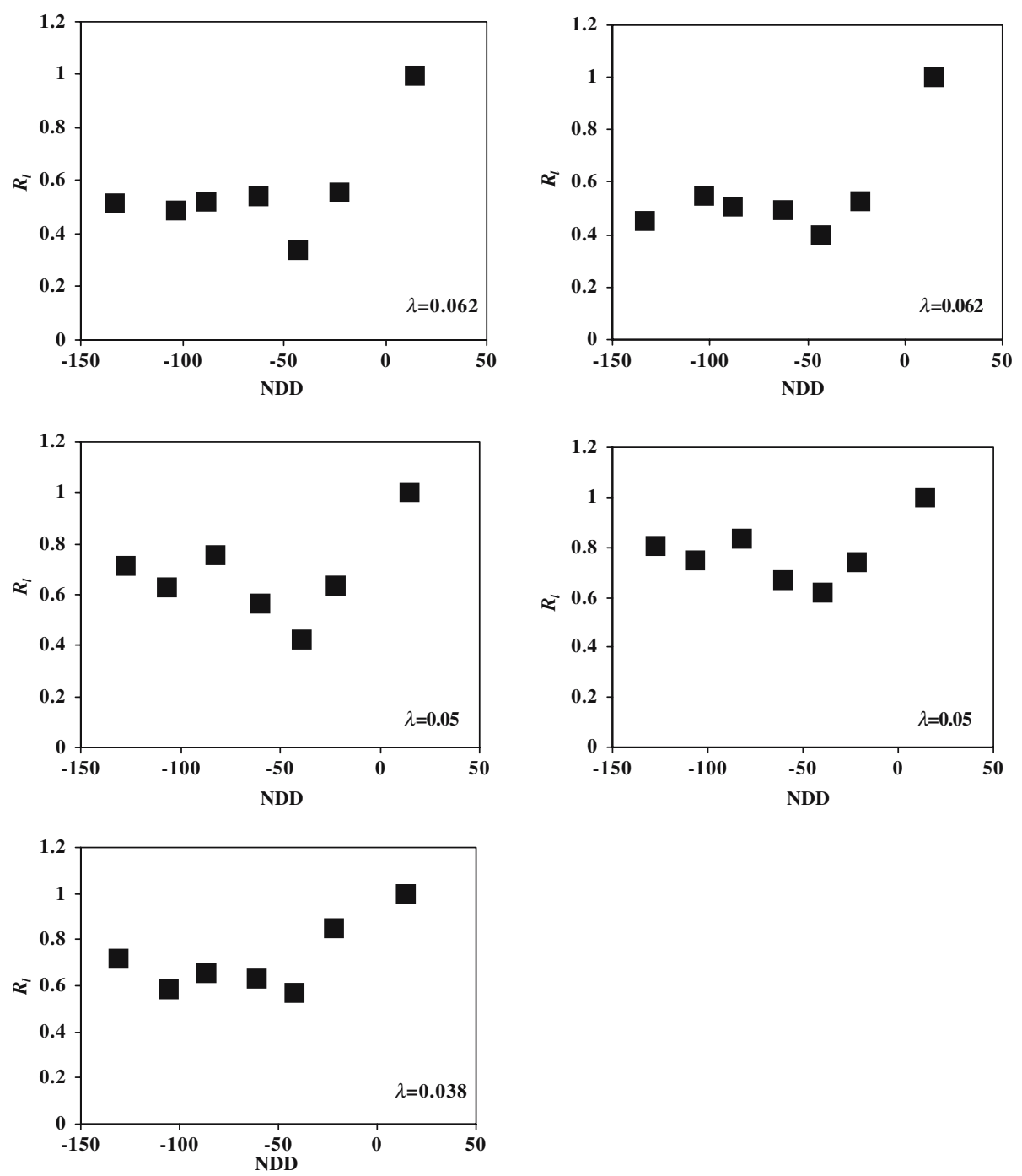

Fig. 15 The pattern of $R_{\mathrm{l}}\left(\tau_{\mathrm{S}}: \tau\right)$ as a function of NDD for four of the roughness arrays showing a shear-stress minimum consistently at $\mathrm{NDD} \approx-42$

the monitoring periods (Table 2), the shear-stress value at each of the interior Irwin sensor locations was divided by the shear-stress value for the Irwin sensor outside of the array. These normalized values define the average 10-min shear-stress ratio. The data from all the Irwin sensors (14-18 depending on the array) and the different monitoring periods were then averaged to estimate the mean and standard deviation of $R$ for an entire array. These values were also calculated using only the data for the instruments that were at NDD $<-42$, which appear to be relatively invariant beyond this distance. The mean $R$ values of the roughness arrays are plotted as a function of $\lambda$ in Fig. 17, where we find considerable variability in the measured $R$ value for each $\lambda$ with the coefficient of variation ranging from a low value of $\approx 0.17$ for $\lambda=0.050$ to 


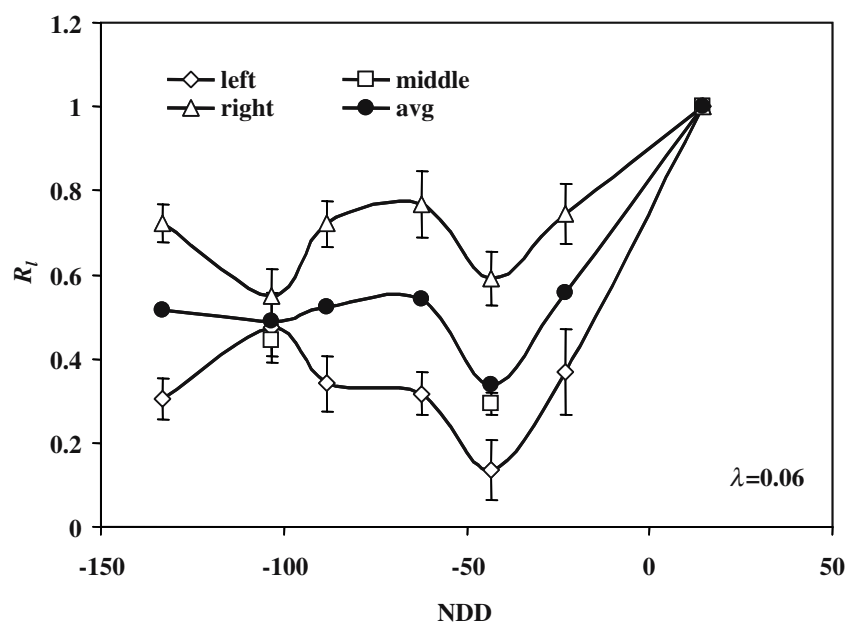

Fig. 16 The pattern of $R_{1}$ with negatively increasing NDD showing that the minimum at NDD $\approx-42$ is apparent at all three Irwin sensors and the average is not biased by just one or two sensors being in zones of lower shear

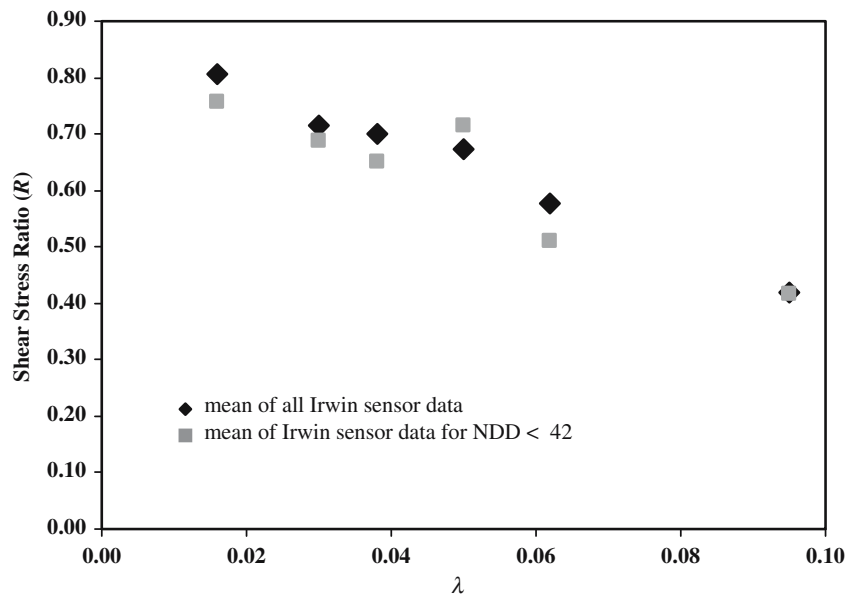

Fig. 17 The mean $R$ value determined with the Irwin sensors for all available sensors (black diamonds) and for just the sensors at NDD $<-42$ (grey squares), which is assumed to be the distance after which $\tau_{\mathrm{S}}$ is in equilibrium in the roughness array

a high value of $\approx 0.74$ for $\lambda=0.095$. The percentage difference between $R$ for all the data and $R$ for the data where NDD $<-42$ ranges between 0.89 and 1.1 .

The appearance of a relatively constant value of $R_{1}$ supports our assumption that the data obtained from analysis of the wind profiles at the apex of the roughness are representative of equilibrium stress conditions. When the partition between between $\tau$ and $\tau_{\mathrm{S}}$ becomes invariant it is difficult to imagine a situation when the wind profile above the surface is not in equilibrium. 


\section{Discussion}

The field instrumentation designed for this study (force balances and Irwin sensors) proved very reliable and practical despite the very harsh field conditions to which they were subjected. The main difference between the experimental data collected at the Jornada and other available field datasets is that the roughness elements used in Jornada were solid, while the other field experiments' roughness elements were comprised of porous vegetation.

The pattern of the shear stress reduction through the roughness arrays can be compared with the observations of Bradley (1968). We note however, that the roughness configuration used by Bradley (1968) was not a staggered array, as in our study, rather his array was regular with each element lining up directly behind another in columns. He noted in his measurements of total shear stress along a step change in roughness that there was a suggestion of a shear-stress minimum as one progressed into the roughness that occurred in a region $2-3 \mathrm{~m}$ into the roughness array. Based on the height of his roughness elements $(0.07 \mathrm{~m})$ the minimum in the Bradley (1968) dataset occurs between NDD $\approx-29$ to -43 , which corresponds to the same position for the observed $\tau_{\mathrm{S}}$ minimum observed for the Jornada data. Based on the data from this experiment as well as those of Bradley (1968), the position of the zone of shear-stress reduction appears to scale as a function of element height.

Kaimal and Finnigan (1994) offer an explanation for the overshoot phenomenon for the total shear stress. In this smooth-to-rough transition the rapidly travelling airstream over the smooth surface generates a high stress upon encountering the roughness. As the rougher surface absorbs momentum from the air layers above it and this region of decelerated flow thickens into an IBL, the velocity of the air layer in contact with the roughness decreases, as does the resulting surface stress (Kaimal and Finnigan 1994). For $\tau_{\mathrm{S}}$ specifically, there is an immediate decrease compared to $\tau$, followed by a maximum reduction in the zone of overshoot, and then a return to an equilibrium $\tau_{\mathrm{S}}$. The majority of the shear stress appears to initially be borne by $\tau_{R}$. One consequence of the pattern of $\tau_{\mathrm{S}}$ changing with downstream distance could be that during sediment transport events the zone of minimum $\tau_{\mathrm{S}}$ becomes a zone of deposition if shear stress is reduced at that location to below the threshold value. In comparison with available wind-tunnel shear-stress partitioning data, the most notable difference is the size of the roughness elements used in the present study, which are on the order of a magnitude taller and 1-10 times wider than those used in prior wind-tunnel studies.

Using the collected data on wind speed, friction velocity, and drag coefficients, combined with the known $\lambda$ values of the roughness arrays, $\tau$ predicted from Eq. 2 (designated henceforth as $\tau_{\mathrm{R} 92}$ ) can be compared to $\tau$ calculated from the anemometer data using Eqs. 8 and 3. The ratio between the measured and calculated $\tau$ for each of the measurement periods defined in Table 2 shows relatively good agreement with the expected one-to-one relationship with an error of approximately $\pm 15 \%$ (Table 5 ). This provides confidence that the Raupach (1992) model defines the general shearstress partition for a roughened surface.

The Irwin sensors allow for a direct measurement of $\tau_{\mathrm{S}}$ for comparison with $\tau_{\mathrm{S}}$ that can be calculated from its component part of Eq. 2 (henceforth $\tau_{\mathrm{SR} 92}$ ) using the available wind speed and drag coefficient data. As $\lambda$ increases the ratio of $\tau_{\mathrm{S}}: \tau$ should decrease and as shown in Fig. 18 this was observed for the measured and calculated values. The relationships both show an exponential decrease in this ratio as $\lambda$ increases 
Table 5 The ratio between

$\tau_{\mathrm{R} 92}: \tau, \tau_{\mathrm{S} 92}: \tau_{\mathrm{S}}$, and $\tau_{\mathrm{S}}: \tau$ based on the available $10-\mathrm{min}$ average data for each roughness density

\begin{tabular}{|c|c|c|c|c|c|c|}
\hline \multirow[t]{2}{*}{$\lambda$} & \multicolumn{2}{|c|}{$\tau_{\mathrm{R} 92}: \tau$} & \multicolumn{2}{|c|}{$\tau_{\mathrm{SR}} 92: \tau_{\mathrm{S}}$} & \multicolumn{2}{|l|}{$\tau_{\mathrm{S}}: \tau$} \\
\hline & mean & $\mathrm{SD}$ & mean & SD & mean & $\mathrm{SD}$ \\
\hline 0.016 & 0.934 & 0.284 & 1.988 & 0.793 & 0.457 & 0.462 \\
\hline 0.030 & 0.927 & 0.084 & 1.098 & 0.130 & 0.312 & 0.034 \\
\hline 0.038 & 0.914 & 0.146 & 0.818 & 0.131 & 0.342 & 0.058 \\
\hline 0.038 & 1.014 & 0.307 & 0.725 & 0.204 & 0.428 & 0.091 \\
\hline 0.050 & 1.029 & 0.089 & 0.869 & 0.119 & 0.311 & 0.053 \\
\hline 0.050 & 0.991 & 0.192 & 0.841 & 0.163 & 0.309 & 0.064 \\
\hline 0.062 & 0.999 & 0.096 & 0.621 & 0.045 & 0.360 & 0.021 \\
\hline 0.062 & 0.924 & 0.128 & 0.650 & 0.066 & 0.321 & 0.036 \\
\hline 0.095 & 0.925 & 0.309 & 1.316 & 0.203 & 0.109 & 0.027 \\
\hline
\end{tabular}

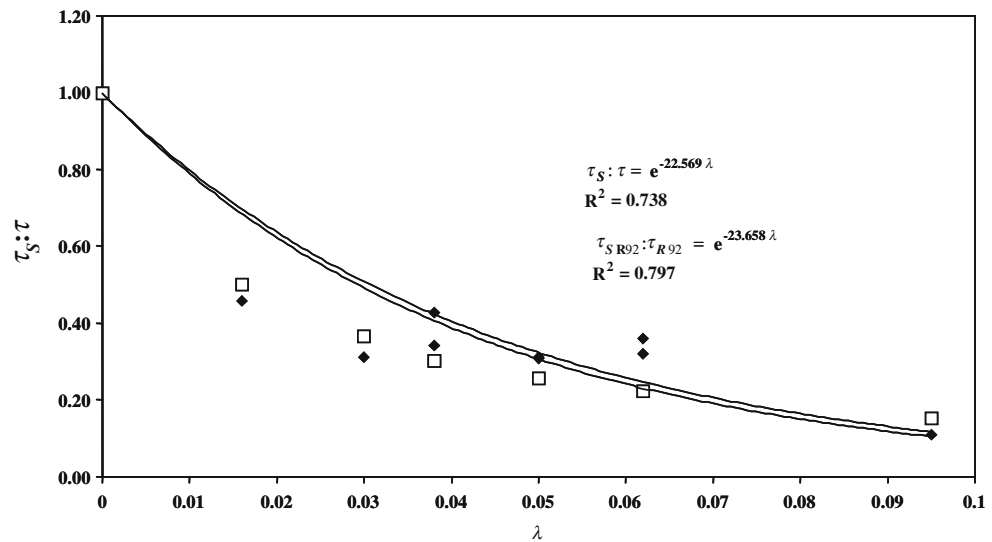

Fig. 18 The modelled (open squares) and measured (black diamonds) ratio of $\tau_{\mathrm{S}}: \tau$ versus $\lambda$

and they compare very well with each other. The average ratio of $\tau_{\mathrm{SR} 92}: \tau_{\mathrm{S}}$ for each measurement period is shown in Table 5 , and although more variable than the $\tau_{\mathrm{R} 92}: \tau$ ratio, it approximates the expected 1:1 relationship considering all cases combined. For all cases the ratio average is 0.992 with a standard deviation of 0.433 .

The data collected in this study compare favourably with available shear-stress data measured in other field experiments (Fig. 19). In comparison with available wind- tunnel shear-stress partitioning data, the Jornada data show, in general, lesser amounts of shear-stress reduction for similar $\lambda$ values (Fig. 19).

When comparing the Raupach et al. (1993) model predicted values of $R_{\mathrm{t}}$ using measured input variables (first assuming $m=0.5$ ) with the Jornada data (Fig. 20), the model predicts higher shear-stress ratio values as compared to the measured values from the Irwin sensors implying a lesser amount of shear-stress reduction than predicted. The best fit of the modelled to the measured values occurs when the $m$ variable is adjusted to a value of 0.7 , which is higher that the reported values of Wyatt and Nickling (1996) and Crawley and Nickling (2003) of 0.16 for porous vegetation and 0.53 to 0.58 for cylinders within a laboratory wind tunnel, respectively.

To further evaluate the validity of the average $R$ values for each roughness configuration obtained with the Irwin sensor measurements, the element drag data can be Springer 


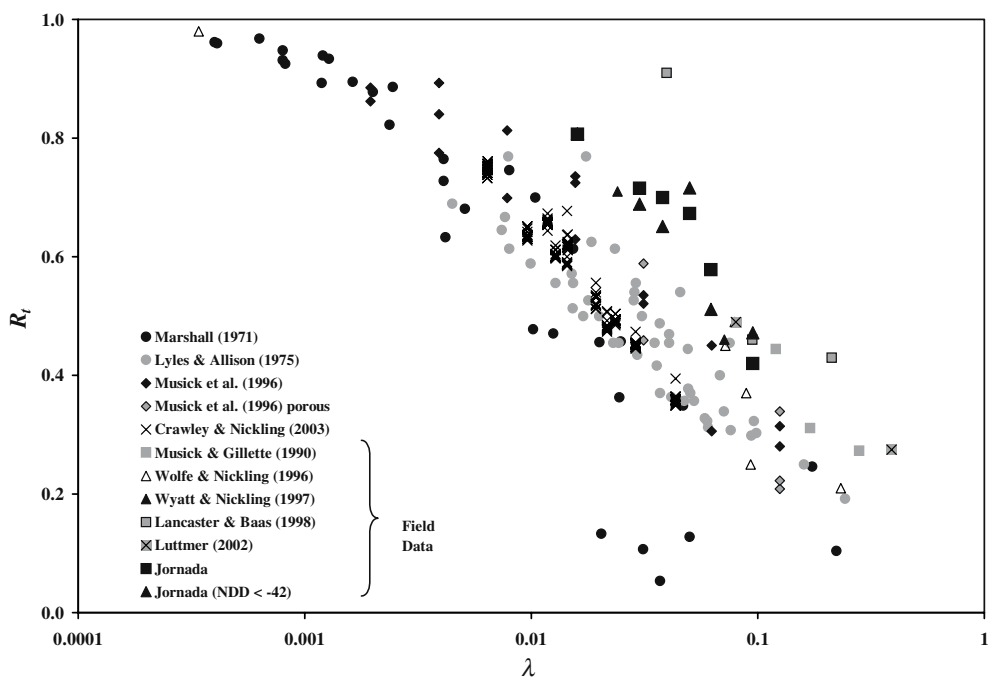

Fig. 19 A comparison between the shear stress ratio $R$ for the Jornada data, data from other field and laboratory studies, and $\lambda$. Solid black squares represent the mean $R$ value at each $\lambda$ for all available Irwin sensor data and the black triangles are the mean $R$ value at each $\lambda$ for Irwin sensor data for positions of NDD $<\approx-42$

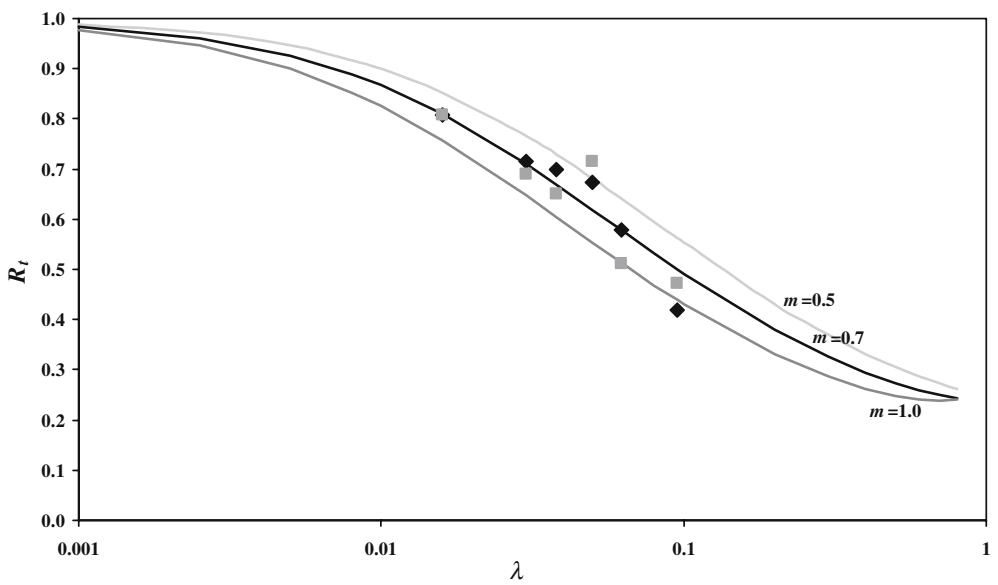

Fig. 20 Comparison between the modelled $R$ values as a function of $\lambda$ for $m=0.5$ (top grey line), $m=0.7$ (middle black line), and $m=1.0$ (bottom grey line) and the mean measured $R$ values obtained from all the available Irwin sensors (black squares) and for just the Irwin sensors at NDD $<\approx-42$ (black triangles)

used to estimate the closure on the shear-stress partitioning relationship. According to Cheng and Castro (2002), surface shear stress attributed to form drag (i.e., $\tau_{\mathrm{R}}$ ) can be estimated by measuring the form drag over a unit area containing one of the roughness elements. For the staggered array configuration used in this study a unit area can be defined based on a geometrical definition similar to that presented by Cheng and Castro (2002) (see their Fig. 1, also Fig. 21 herein). 


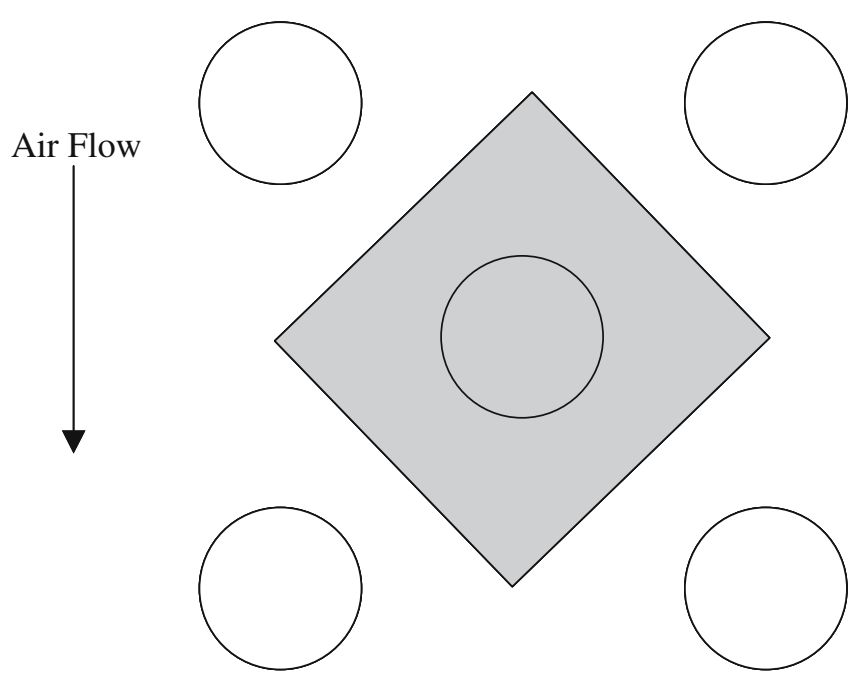

Fig. 21 Roughness element geometry (open circles) and their relationship to unit area (shaded square) as defined similarly to Cheng and Castro (2002)

The surface shear stress in a unit area for high element density that assumes no viscous drag component is defined by Cheng and Castro (2002) as

$$
\tau=\frac{F}{A_{\mathrm{u}}}
$$

where $F$ is the drag force created by the airflow on an individual element and $A_{\mathrm{u}}\left(\mathrm{m}^{2}\right)$ is unit (plan) area of the rough surface (Cheng and Castro 2002).

We have confidence in the performance of the drag balance instrument to measure the applied force on the roughness elements, and as demonstrated earlier, the Irwin sensor data used to estimate $\tau_{\mathrm{S}}$ and $R$ compare favourably with the modelled values of Raupach (1992) (Fig. 18), both modelled $R$ values (Fig. 20), and other field data (Fig. 19). The $A_{\mathrm{u}}$ value for the Jornada data for each roughness configuration can be estimated using the measured $\tau, \tau_{\mathrm{S}}$, and average force $(F)$ on drag-balance mounted elements inside the roughness arrays. The solution for the appropriate $A_{\mathrm{u}}\left(\mathrm{in}^{2}\right)$ for each valid 10-min average is simply

$$
A_{\mathrm{u}}=\frac{F}{\left(\tau-\tau_{\mathrm{S}}\right)} .
$$

The average $A_{\mathrm{u}}$ values for five of the roughness arrays plotted against $\lambda$ are shown in Fig. 22, and for comparison, the relationship between $A_{\mathrm{u}}$ as defined in Fig. 21 and $\lambda$ also is shown. The relationship in Fig. 22 shows that $A_{\mathrm{u}}$ should increase geometrically as the centre-to-centre distance between elements increases, and the number of elements decreases in a given area, reducing $\lambda$ proportionally. The estimated values of $A_{\mathrm{u}}$ for the low density arrays show considerable variation from the expected $A_{\mathrm{u}}$ as indicated in the large standard deviation around the mean values. This is likely due to the wider distribution of turbulent eddy sizes the increasingly exposed elements experience, and the likely non-uniformity of $\tau_{\mathrm{S}}$. As the arrays become denser the estimated values are closer to those of the geometric model. 


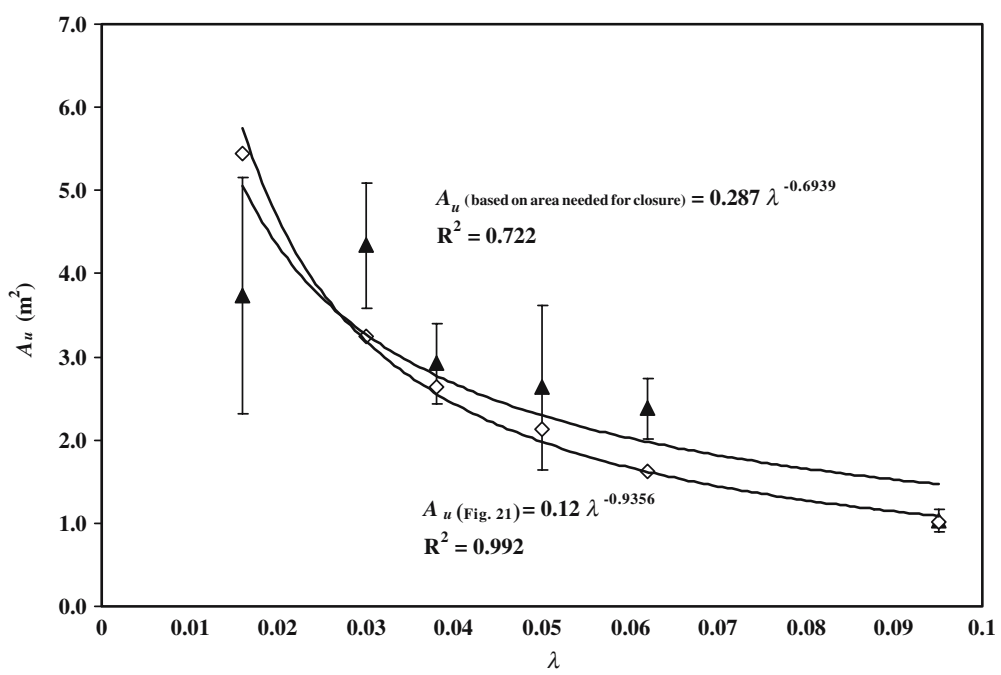

Fig. 22 Relationship between the $A_{\mathrm{u}}$ for determining $\tau_{\mathrm{R}}$ based on knowledge of the drag force on a roughness element using the geometric model presented in Fig. 21 (open diamonds), compared with the relationship between the estimated $A_{\mathrm{u}}$ (black triangles) required to obtain closure on the relationship $\tau_{\mathrm{S}}+\tau_{\mathrm{R}}=\tau$ based on Irwin sensor and drag balance measurements of $\tau_{\mathrm{S}}$ and $\tau_{\mathrm{R}}$ and wind speed profile measurements to estimate $\tau$

One other comparison that can be made using the two different measurement methods to quantify the effect of drag and shear stress reduction by roughness is between $R$ derived with the Irwin sensor data and NED derived from the force balance data. The relationship between average $R$ and average NED (at NDD $\approx-100$ ) for each $\lambda$ is shown in Fig. 23, and as expected, $R$ scales with NED over the range of roughness densities tested. The pattern of change in $R$ and NED as a function of NDD are slightly different, with $\tau_{\mathrm{S}}$ initially declining rapidly, reaching a minimum and then recovering to an equilibrium value, while NED shows a continual decline as a function of NDD. However, a drag balance located at NDD $\approx-42$ may have shown an increase in NED in relation to other drag balances interior to the array, as this is the region of the $\tau$ overshoot.

$\mathrm{Li}$ and Shao (2003) suggested that the Raupach et al. (1993) model cannot be applied beyond $\lambda \geq 0.1$. This makes the relationship shown in Fig. 23 very useful from a practical point of view. Based on our experience, it was more practical, and data were obtained with greater confidence using the drag balances, to obtain element drag force measurements than making surface shear-stress measurements with the Irwin sensors. The drag balance relied on calibration with a primary standard (mass $x$ acceleration due to gravity) while the Irwin sensors required calibration via the calculation of $\tau$ from wind speed profile data. This variable has greater uncertainty due to uncertainties in the wind speed measurements, heights of the anemometer, and the regression procedures involved (once for the calculation of $\tau$, and again for the $\tau$ versus output relationship). Using drag balances to obtain NED values should allow for a reasonable estimation of the surface shearing stress for a surface with $\lambda$ between $0.03-0.10$. Based on the previous work of Gillies et al. $(2000,2002)$ measurements of NED to evaluate $\tau_{\mathrm{S}}$ could be extended to sparse vegetation community structures 


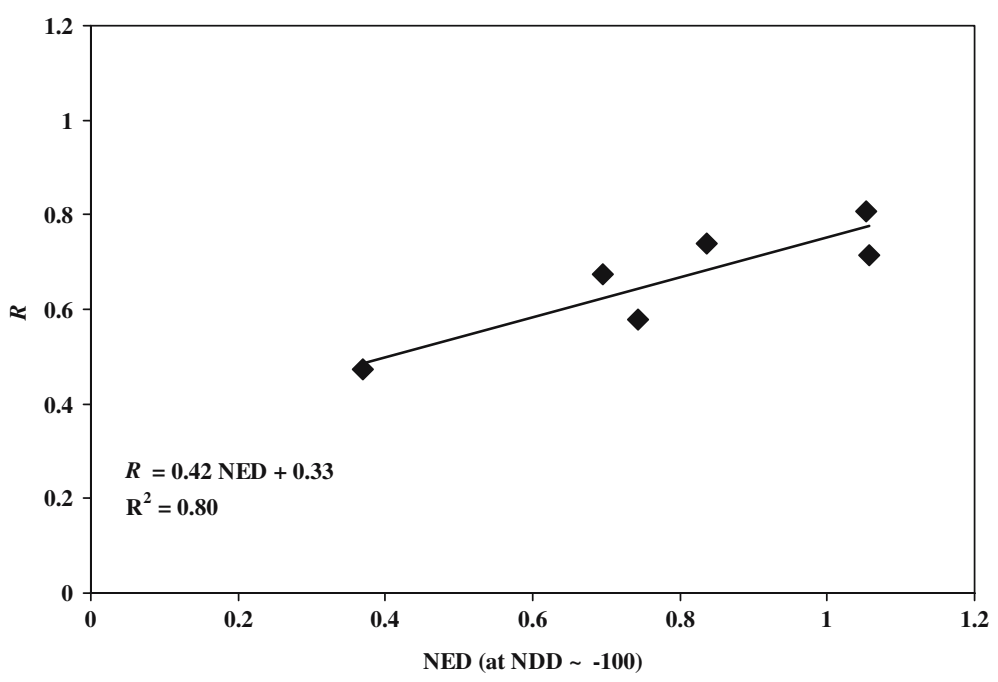

Fig. 23 Relationship between $R$ and NED (at NDD $\approx-100$ ) for each $\lambda$

as individual plants can be attached to the drag balances to obtain measurements of plant drag force measurements.

\section{Conclusions}

The measurement of shear-stress partitioning was undertaken at the field scale in the atmospheric ISL in patches of roughness $\approx 60 \mathrm{~m}$ in length composed of large roughness elements of various roughness densities. The instruments utilized measured the total shear stress and its components attributable to the intervening surface and the roughness elements. It was successfully demonstrated that Irwin sensors could be used to measure surface shear-stress in the ISL at the field scale and, more importantly, that the very rugged and robust drag balances could be used potentially by themselves to provide a good estimate of the surface shear stress for surfaces with roughness density between 0.03 and 0.1 . Importantly, the relationship would have to be evaluated for plants, as $\tau_{\mathrm{R}}$ would likely be influenced by the plants porosity and flexibility characteristics.

The shear-stress partitioning model of Raupach (1992) and Raupach et al. (1993) proved to perform very well in predicting the amount of surface shear stress knowing the stated input parameters. The $\tau_{\mathrm{S}}$ measurements through the length of the roughness arrays combined with previous data presented in Bradley (1968) suggest that the zone of $\tau_{\mathrm{S}}$ "undershoot" observed at NDD $\approx-42$ coincides with the position of the overshoot of $\tau$ (Kaimal and Finnigan 1995) and its position into the roughness scales primarily with the element height. This suggests that smaller roughness will reach equilibrium shear-stress conditions much faster than larger elements in a smooth-to-rough transition and the model can be applied with more confidence for smaller patches composed of smaller roughness elements.

The presence of a zone of $\tau_{\mathrm{S}}$ "undershoot" also has implications for depositional processes during aeolian sediment transport events. The zone of maximum surface Springer 
shear-stress reduction could provide an area in which, over time, there is a net deposition of sediment compared to the total patch length. During transport events this shear stress could drop below the threshold for transport resulting in deposition and an eventual thickening of deposited material in this region. Field measurements of sediment thickness in patches of roughness where sand transport occurs could reveal if this phenomenon influences the depositional history of those patches.

Based on the results of this study it is argued that the Raupach et al. (1993) model provides a useful basis for evaluating airflow and potentially sediment transport for patches of roughness of varying size mixed among larger sandy deposits. This type of roughness is observed in arid terrestrial deserts, in the McMurdo Dry Valley system, Antarctica, some beach environments, and certainly on the surface of Mars.

Acknowledgements This research was funded through the NASA, Mars Fundamental Research Program (Grant, NAG5-12759). W.G. Nickling gratefully acknowledges the financial support of the Natural Sciences and Engineering Research Council of Canada (Grant 7427-02). Logistical support from the USDA Jornada Experimental Range Personnel was greatly appreciated and instrumental in the success of this project. The authors would like to thank Shannon Brown and Jennifer Bryant from the University of Guelph for their assistance in instrument set-up and diligence in keeping the field site in operation. Kurt Cupp of the Desert Research Institute ably assisted in the instrument fabrication, set-up, and programming of the data acquisition systems as part of this project. Mario Finoro and Sandy McLaren of the University of Guelph also contributed to the instrument design and fabrication. Thanks finally to the Torin Macpherson, Matt Alexander, Andrew Torcoletti, Jennifer Booth and Laura Brown from the University of Guelph who participated as part of the JER field studies, and to Dr. Dale and Mrs. Jane Gillette for their support while at the JER.

\section{References}

Bradley EF (1968) A micrometeorological study of velocity profiles and surface drag in the region modified by a change in surface roughness. Quart J Roy Meteorol Soc 94:361-379

Cheng H, Castro IP (2002) Near wall flow over urban-like roughness. Boundary-Layer Meteorol 104:229-259

Crawley D, Nickling WG (2003) Drag partition for regularly-arrayed rough surfaces. Boundary-Layer Meteorol 107:445-468

Finnigan JJ (1979) Turbulence in waving wheat I. Mean statistics and honami. Boundary-Layer Meteorol 16:181-211

Garratt JR (1990) The internal boundary layer - a review. Boundary-Layer Meteorol 50:171-203

Gillette DA, Chen W (2001) Particle production and aeolian transport from a "supply-limited" source area in the Chihuahuan Desert, New Mexico, United States. J Geophys Res 106(D6):5267-5278

Gillette DA, Clayton RN, Mayeda TK, Jackson ML, Sridhar K (1978) Tropospheric aerosols from some major dust storms of the southwestern United States. J Appl Meteorol 17:832-845

Gillette D, Herrick J, Herbert G (2006) Wind characteristics of mesquite streets in the Northern Chihuahuan Desert, New Mexico, USA. Environ Fluid Mech 6(3):241-275

Gillies JA, Lancaster N, Nickling WG, Crawley D (2000) Field determination of drag forces and shear stress partitioning effects for a desert shrub (Sarcobatus vermiculatus, Greasewood. J Geophys Res Atmos 105(D20):24871-24880

Gillies JA, Nickling WG, King J (2002) Drag coefficient and plant form-response to wind speed in three plant species: Burning Bush (Euonymus alatus), Colorado Blue Spruce (Picea pungens glauca.), and Fountain Grass (Pennisetum setaceum). J Geophys Res Atmos 107(D24):10-1 $10-15$

Gillies JA, Nickling WG, King J (2006) Aeolian sediment transport through large patches of roughness in the atmospheric inertial sublayer. J Geophys Res - Earth Surface 111, F02006, doi:10.1029/2005JF000434

Irwin HPAH (1980) A simple omnidirectional sensor for wind tunnel studies of pedestrian level winds. J Wind Eng Ind Aero 7:219-239

Jackson PS (1981) On the displacement height in the logarithmic velocity profile. J Fluid Mech 111:15-25 
Kaimal JC, Finnigan JJ (1994) Atmospheric boundary layer flows: their structure and measurement. Oxford University Press, New York, 289 pp

King J, Nickling WG, Gillies JA (2005) Representation of vegetation and other non-erodible elements in aeolian shear stress partitioning models for predicting transport threshold. J Geophys Res Earth Surface 110, F04015, doi:10.1029/2004JF000281

Kutzbach JE (1961) Investigations of the modification of wind profiles by artificially controlled surface roughness. In: Lettau HH (ed) Studies of the three-dimensional structure of the planetary boundary layer. pp 71-113

Lancaster N, Baas A (1998) Influence of vegetation cover on sand transport by wind: field studies at Owens Lake California. Earth Surf Process Landf 25:68-82

Lettau HH (1969) Note on aerodynamic roughness parameter estimation on the basis of roughness element description. Appl Meteorol 8:828-832

Li A, Shao Y (2003) Numerical simulation of drag partition over rough surfaces. Boundary-Layer Meteorol 108:317-342

Luttmer C (2002) The partition of drag in salt grass communities. MS thesis, Guelph, Guelph, ON, Canada

Lyles L, Allison BE (1975) Wind erosion: Uniformly spacing nonerodible elements eliminates effects of wind direction variability. J Soil Water Conserv 30:225-226

MacDonald RW, Griffiths RF, Hall DJ (1998) An improved method for the estimation of surface roughness of obstacle arrays. Atmos Environ 31(11):1857-1864

Malin MC, Carr MH, Danielson GE, Davies ME, Hartmann WK, Ingersoll AP, James PB, Masursky H, McEwen AS, Soderblom LA, Thomas P, Veverka J, Caplinger MA, Ravine MA, Soulanille TA, Warren JL (1998) Early views of the Martian surface from the Mars Orbiter Camera of Mars Global Surveyor. Science 279(5357):1681-1685

Marshall JK (1971) Drag measurements in roughness arrays of varying density and distribution. Agric Meteorol 8:269-292

Monteiro JP, Viegas DX (1996) On the use of Irwin and Preston wall shear stress probes in turbulent incompressible flows with pressure gradients. J Wind Eng Ind Aero 64:15-29

Musick HB, Gillette DA (1990) Field evaluation of relationships between a vegetated structural parameter and sheltering against wind erosion. Land Degrad Rehab 2:87-94

Musick HB, Trujillo SM, Truman CR (1996) Wind-tunnel modelling of the influence of vegetation structure on saltation threshold. Earth Surf Process Landf 21(7):589-605

Okin GS, Gillette DA (2001) Distribution of vegetation in wind-dominated landscapes: Implications for wind erosion modeling and landscape processes. J Geophys Res 106(D9):9673-9683

Panofsky HA, Townsend AA (1964) Change of terrain roughness and the wind profile. Quart J Roy Meteorol Soc 90:147-155

Rao KS, Wyngaard JC, Coté OR (1974) The structure of two-dimensional internal boundary layer over a sudden change of surface roughness. J Atmos Sci 31:738-746

Raupach MR (1992) Drag and drag partition on rough surfaces. Boundary-Layer Meteorol 60:375-395

Raupach MR, Gillette DA, Leys JF (1993) The effect of roughness elements on wind erosion threshold. J Geophys Res 98(D2):3023-3029

Raupach MR, Thom AS, Edwards I (1980) A wind-tunnel study of turbulent flow close to regularly arrayed rough surfaces. Boundary-Layer Meteorol 18:373-397

Schlichting H (1936) Experimentelle untersuchungen zum rauhigkeitsproblem. Ingen - Arch 7:1-34

Taylor PA (1988) Turbulent wakes in the atmospheric boundary layer. In: Steffen WL, Denmead OT (eds) Flow and transport in the natural environment: advances and application. Springer-Verlag, Berlin, pp 270-292

Thom AS (1971) Momentum absorption by vegetation. Quart J Roy Meteorol Soc 97:414-428

Wieringa J (1993) Representative roughness parameters for homogeneous terrain. Boundary-Layer Meteorol 63:323-363

Wilson SA, Zimbelman JR (2004) Latitude-dependent nature and physical characteristics of transverse aeolian ridges on Mars. J Geophys Res 109:E10003, doi: 10.1029/2004JE002247

Wolfe SA, Nickling WG (1996) Shear stress partitioning in sparsely vegetated desert canopies. Earth Surf Process Landf 21:607-619

Wooding RA, Bradley EF, Marshall JK (1973) Drag due to regular arrays of roughness elements of varying geometry. Boundary-Layer Meteorol 5:285-308

Wu H, Stathopoulos T (1994) Further experiments on Irwin's surface wind sensor. J Wind Eng Ind Aero 53:441-452

Wyatt V, Nickling WG (1997) Drag and shear stress partitioning in sparse desert creosote communities. Can J Earth Sci 34:1486-1498 